\title{
Predicate fronting in Yiddish and conditions on multiple copy Spell-Out
}

\author{
Isaac L. Bleaman ${ }^{1}$
}

Received: 20 September 2016 / Accepted: 12 March 2021 / Published online: 26 March 2021

(C) The Author(s) 2021

\begin{abstract}
Predicate fronting with doubling (also known as the predicate cleft) has long been a challenge for theories of syntax that do not predict the pronunciation of multiple occurrences. Previous analyses that derive the construction via syntactic movement, including those attributing verb doubling to the formation of parallel chains (e.g., Aboh 2006; Kandybowicz 2008), are incompatible with remnant movement (Müller 1998), which does not give rise to doubling. This article presents data from the predicate fronting construction in Yiddish, in which verbs always double but complements never do. I argue that these seemingly contradictory pronunciation facts can be reconciled even if one assumes that phrasal movement and head movement are both syntactic. More specifically, the pronunciation of occurrences in Yiddish (doubled or not) follows from the general conditions on Spell-Out (or Transfer ${ }_{\mathrm{PF}}$ ) defined by Collins and Stabler (2016), modified only to accommodate syntactic head movement. Post-syntactic PF repairs are thus not required to account for the facts of the Yiddish predicate fronting construction. If such repairs are needed to generate doubling phenomena in other languages, they should be explicitly defined so as to modify or override the predictions of default Spell-Out conditions.
\end{abstract}

Keywords Predicate cleft · Remnant movement - Multiple copy pronunciation · Spell-Out · Yiddish

\section{Introduction}

Predicate fronting with doubling, also known as the predicate cleft, has long posed a problem for theories of syntax that predict the pronunciation of just one occurrence

$\triangle$ I.L. Bleaman

bleaman@berkeley.edu

1 Department of Linguistics, University of California, Berkeley, 1203 Dwinelle Hall \#2650,

Berkeley, CA 94720-2650, USA 
of a moved element. The basic pattern is illustrated with an example from Yiddish (1), which will be the focus of this article. (Doubled elements will always be printed in boldface.)
a. ikh red mame-loshn.
I speak.1.SG mama-language 'I speak Yiddish.'
(Davis and Prince 1986:90, ex. 2-a)
b. red-n/*red
red
ikh mame-loshn.
speak-INF/*speak.1.SG speak.1.SG I mama-language
'As for speaking, I speak Yiddish.' (Davis and Prince 1986:90, ex. 2-b)

In several respects, the Yiddish pattern is typical of the predicate fronting construction that has been documented in many typologically diverse languages (see Kandybowicz 2008:80 for a list of references). First, when a finite verb is topicalized, two copies are obligatorily pronounced-the higher copy marked with non-finite morphology, and the lower copy marked for tense. ${ }^{1}$ Second, as in Hebrew (Landau 2006), Polish (Bondaruk 2009), and Russian (Aboh and Dyakonova 2009), verbs in Yiddish can be topicalized along with their complements (2), suggesting that the fronting operation can target a phrase rather than a bare verbal head. Regardless of where the complement is pronounced-whether after the second copy of the verb (1-b) or after the first copy (2)-it is never doubled.

$$
\begin{array}{llll}
\text { red-n mame-loshn } & \text { red } & \text { ikh } & (* \text { mame-loshn). } \\
\text { speak-INF mama-language speak.1.SG I } & \text { (*mama-language) }
\end{array}
$$

'As for speaking Yiddish, I speak it.'

If both patterns involve VP movement (evidence for this view will be presented in Sect. 2), then the syntax should have some principled way of accounting for the obligatory doubling of verbs and the obligatory non-doubling of complements.

The goal of this article is to arrive at a set of explicit conditions on Spell-Out that account for these seemingly contradictory pronunciation facts. I will show that they actually follow from quite general principles governing the pronunciation of syntactic objects, defined by Collins and Stabler (2016) and modified only to accommodate syntactic head movement. Adopting such explicit conditions on Spell-Out-an algorithm—serves two purposes: (i) the conditions show precisely why the predicate fronting construction is initially problematic (i.e., applying them to derivations makes

\footnotetext{
${ }^{1}$ In this article, examples are limited to cases involving a fronted infinitive. For data on a different pattern involving fronted participles, see Davis and Prince (1986) and Cable (2004).

${ }^{2}$ Unless otherwise indicated, example sentences were elicited during consultation sessions conducted by the author in Yiddish with three native speakers: Lieb Herskovits (Transcarpathian Yiddish), Binyumen Schaechter (Southeastern Yiddish), and Yankl Shvaytser (Transcarpathian Yiddish). Herskovits grew up in the Hasidic community of Kiryas Tosh in Quebec and lives in Brooklyn, New York. Schaechter was raised in a secular Yiddishist home in the Bronx and speaks Yiddish with his family. Shvaytser is a Vizhnitzer Hasid who lives in a religious Yiddish-speaking community in Upstate New York and writes professionally for Yiddish-language periodicals. Despite otherwise noteworthy differences between the Transcarpathian and Southeastern dialects, the consultants agreed on their judgments. (Previously published examples that are cited here were also verified by the consultants.)
} 
incorrect predictions), and (ii) they show how the predictions are altered when modifications are introduced to handle an ostensibly unrelated phenomenon: syntactic head movement.

The rest of the article is organized as follows: Sect. 2 provides evidence for a movement-based approach to the verb doubling construction in Yiddish. Sect. 3 defines the initial set of conditions on Spell-Out (or Transfer ${ }_{\mathrm{PF}}$ ), which are drawn from the minimalist framework of Collins and Stabler (2016) and assume the copy theory of movement. These Spell-Out conditions make correct predictions with respect to the obligatory non-doubling of complements (under remnant movement), but they require modification in order to capture syntactic head movement, a phenomenon that Collins and Stabler (2016) do not address. Specifically, an update is needed to prevent the pronunciation of multiple occurrences of moved heads - an incorrect prediction of the original Spell-Out conditions. Sect. 4 demonstrates why a natural consequence of this independently necessary modification is verb doubling in the predicate fronting construction in Yiddish (if not also in a closely related language, German). Finally, Sect. 5 presents some conclusions about the nature of PF repairs, arguing that if they are necessary to account for other kinds of doubling phenomena, then they must be defined in such a way that they modify or override the predictions of the default Spell-Out conditions.

\section{Movement}

In the literature on the verb doubling construction in Yiddish, most syntacticians have concluded that the first occurrence of the verb is the result of movement (Waletzky 1980; Davis and Prince 1986; Källgren and Prince 1989; Hoge 1998; Cable 2004). Although many details of their analyses differ, ${ }^{3}$ the basic evidence for movement is widely accepted.

\subsection{Evidence for movement}

Yiddish exhibits the Germanic verb-second (V2) pattern, as shown in (3).
a. ikh ken dem rov.
I know.1.SG the.ACC rabbi
'I know the rabbi.'
b. *zikher ikh ken dem rov.
certainly I know.1.SG the.ACC rabbi
'Certainly I know the rabbi.'
c. zikher ken ikh dem rov. certainly know.1.SG I the.ACC rabbi
'Certainly I know the rabbi.'

\footnotetext{
${ }^{3}$ Both Hoge (1998) and Cable (2004) propose the independent base-generation of two copies of the verb, where one of the copies moves to the left periphery. The approach pursued here follows Davis and Prince (1986) and Källgren and Prince (1989) in assuming that only one verb is externally merged.
} 
Like the adverb zikher 'certainly,' topicalized objects must immediately precede the finite verb (4). Left-dislocated DPs, however, cannot (5). Note also that the topicalized object in Yiddish is marked for the accusative case, which is not a requirement of left-dislocated DPs.
a. *der/*dem rov ikh ken. the.NOM/ACC rabbi I know.1.SG 'I know the rabbi.'
b. dem rov ken ikh. the.ACC rabbi know.1.SG I 'I know the rabbi.'
c. *der rov ken ikh. the.NOM rabbi know.1.SG I 'I know the rabbi.'
a. der/dem rov, ikh ken im.
the.NOM/ACC rabbi I know.1.SG him.ACC
'The rabbi, I know him.'
b. *der/*dem rov, ken ikh im.
the.NOM/ACC rabbi know.1.SG I him.ACC
'The rabbi, I know him.'

Finally, like the adverb in (3) and the topicalized object in (4)-but unlike the leftdislocated DP in (5) - the initial infinitive in the verb doubling construction must immediately precede the finite copy (6). The fact that the infinitive is considered a preverbal constituent with respect to V2 has been taken as evidence that it does indeed move to that position (e.g., Davis and Prince 1986; Källgren and Prince 1989). The same is true for sentences in which the initial constituent clearly appears to be an entire VP, the infinitive along with its complement (7).
a. *red-n, ikh red mame-loshn. speak-INF I speak.1.SG mama-language
'As for speaking, I speak Yiddish.'
b. red-n red ikh mame-loshn. speak-INF speak.1.SG I mama-language 'As for speaking, I speak Yiddish.' (repeat of $(1-b))$
(7) a. *red-n mame-loshn, ikh red. speak-INF mama-language I speak.1.SG 'As for speaking Yiddish, I speak it.'
b. red-n mame-loshn red ikh. speak-INF mama-language speak.1.SG I 'As for speaking Yiddish, I speak it.'

Additional support for the movement analysis comes from the domain of island effects. As Davis and Prince (1986) report, the first copy of the verb ${ }^{4}$ can cross finite

\footnotetext{
${ }^{4}$ The form glossed as an "infinitive" in (8) is actually not the irregular citation form visn know.INF but the verbal stem veys with the infinitival suffix $-n$. For this reason, the fronted verb has sometimes been called a
} 
clause boundaries (8-a), ${ }^{5}$ but it cannot be extracted from a relative clause (8-b) or a $w h$-island (8-c). My consultants also do not accept sentences in which the verb has been extracted from an adjunct island (8-d) or a coordinate structure (8-e).

a. veys- $n$ hostu mir gezogt az er veys-t a sakh.

know-INF have.you me.DAT say.PTCP that he know-3.SG a lot

'As for knowing, you told me that he knows a lot.'

(Davis and Prince 1986:92, ex. 11-a)

b. *veys-n hob ikh gezen dem yid-n vos veys-t a sakh.

know-INF have I see.PTCP the Jew-ACC that know-3.SG a lot

'As for knowing, I saw the man that knows a lot.'

(Davis and Prince 1986:92, ex. 12-a)

c. *veys-n hostu mir gezogt ver es veys-t a sakh.

know-INF have.you me.DAT say.PTCP who EXPL know-3.SG a lot

'As for knowing, you told me who knows a lot.'

(Davis and Prince 1986:93, ex. 13-a)

d. *veys-n vel ikh im freg-n nokh dem vi er veys-t dem

know-INF will I him.ACC ask-INF after that as he know-3.SG the

entfer.

answer

'As for knowing, I will ask him after he knows the answer.'

e. *veys-n farshtey-t er di frage un veys-t dem

know-INF understand-3.SG he the question and know-3.SG the

entfer.

answer

'As for knowing, he understands the question and knows the answer.'

These island sensitivities hold of other fronted constituents, including $w h$-items, but are not characteristic of left-dislocated DPs in Yiddish; a few examples are provided in (9) and (10). This suggests that while left-dislocated DPs are externally merged in a left peripheral position, ${ }^{6} w h$-items and the infinitive of the predicate fronting construction both move to the left periphery.

\footnotetext{
“pseudoinfinitive” (Mark 1978; Waletzky 1980; Källgren and Prince 1989; Hoge 1998; Cable 2004). I refer readers to those analyses for proposals on how the pseudoinfinitive is derived, including the more peculiar tense-marked first-person and third-person forms bin-en am-INF and $i z-n$ is-INF, which incidentally my consultants do not accept at all. Zaretski (1929), Waletzky (1980), and Hoge (1998) also provide examples of sentences where the fronted verb is the irregular infinitive zayn 'be,' rather than bin-en or iz- $n$.

${ }^{5}$ One of my consultants (Herskovits) was reluctant to accept sentence (8-a) from Davis and Prince (1986). He said it is unnatural to begin a sentence with veys- $n$, a pseudoinfinitive, unless it is immediately followed by a conjugated form like veys- $t$. He did, however, accept a different sentence illustrating movement across a finite clause boundary:
}

(i) red-n meyn ikh red-t er yidish.

speak-INF think I speak-3.SG he Yiddish

'As for speaking, I think he speaks Yiddish.'

${ }^{6}$ While Davis and Prince (1986) assume that left-dislocated elements are base-generated in the left periphery, this is not crucial for our purposes. See Alexiadou (2006) for an overview of possible approaches, as well as Ott (2014), a more recent analysis that derives left-dislocation via movement in a biclausal structure followed by ellipsis. 
a. vos hostu mir gezogt zol-n mir es-n? what have.you me.DAT say.PTCP should-1.PL we eat-INF 'What did you say we should eat?'

b. *vos hostu gezen dem yid-n vos es-t?

what have.you see.PTCP the Jew-ACC that eat-3.SG

'What did you see the man that eats?'

c. *vos hostu mir gezogt zol-n mir es-n un broyt? what have.you me.DAT say.PTCP should-1.PL we eat-INF and bread 'What did you say we should eat and bread?'

(10) a. dos yingl, du host mir gezogt az du ken-st *(im). the boy you have me.DAT say.PTCP that you know-2.SG *(him) 'The boy $i$, you said that you know him $i$.'

b. dos yingl, ikh hob gezen dem yid-n vos ken *(im). the boy I have see.PTCP the Jew-ACC that know.3.SG *(him) 'The boy $_{i}$, I saw the man who knows him $i$.'

c. dos yingl, ikh ze *(im) un zayn shvester. the boy I see *(him) and his sister 'The boy $i$, I see himi and his $_{i}$ sister.'

These diagnostics have also been invoked in the analysis of predicate fronting and doubling in other languages (e.g., Abels 2001 for Russian; Landau 2006 for Hebrew; Bastos-Gee 2009 for Brazilian Portuguese). Such island effects are cited as evidence not only of movement in general, but also of the copy theory of movement in particular, since the pronunciation of an ordinarily silent occurrence suggests that syntactic movement must involve full copies rather than traces.

One observation that has been cited as "definitive evidence against any movement account" of the verb doubling construction (Cable 2004:4) is the apparent possibility of a lexical mismatch between the two verbs, "if and only if [the first verb] denotes a topic which the [second verb] provides more specific information about" (Cable 2004:9). A minimal pair is provided in (11); the question mark on (11-a) is copied directly from Cable (2004), while the star on (11-b) is extrapolated from his discussion.

a. ?for-n keyn amerike bin ikh gefloygn keyn nyu-york. travel-INF to America am I fly.PTCP to New York 'As for traveling to America, I flew to New York.'

(Cable 2004:9, ex. 16-a)

b. *fli-en keyn nyu-york bin ikh geforn keyn amerike.

fly-INF to New York am I travel.PTCP to America 'As for flying to New York, I traveled to America.'

Cable cites this mismatch as evidence that two verbs are base-generated independently. He does not provide a mechanism for ensuring a particular relationship between the two verbs (e.g., similarity or identity), or an explanation for the unacceptability of a mismatch involving a single verb in the left periphery with a coordinate structure below (like (8-e)). To account for the non-doubling of complements, which are also base-generated twice, one must assume a "strange condition on ellipsis" (Cable 2004:20-21) stipulating that one of two identical complements must be elided if 
and only if the head of the left peripheral VP is identical to the lower verbal head. (The verb, which is doubled rather than elided, is thus not subject to such a condition.) Again, there is no mechanism for determining which of the two complements is elided.

Cable's mismatched examples from Yiddish have been reprinted numerous times in the predicate fronting literature on other languages (like Hebrew, Landau 2006:45; Dàgáárè, Hiraiwa and Bodomo 2008:821; Asante Twi, Hein 2017:8), precisely because those languages disallow mismatched predicates. However, I believe a mismatch is disallowed in Yiddish, too: None of the Yiddish grammars that discuss predicate fronting (e.g., Zaretski 1929; Mark 1978) mention the possibility of mismatched predicates, and I could not find any such examples through targeted searches in online corpora. My three consultants unequivocally rejected both sentences in (11). Finally, even Cable's own primary consultant, Dovid Braun, confirmed with me that the example marked with a question mark (11-a) is extremely marginal, if acceptable at all. ${ }^{7}$ For these reasons, I believe the reported judgments should not be relied upon as evidence that Yiddish actually allows mismatched predicates.

Cable states that the contrast between (11-a) and (11-b) is likely to have a semantic explanation. After all, whatever rules out (11-b) could also account for the unacceptability of its English translation, even though the English "as for" construction may not involve movement at all. ${ }^{8}$ Note, additionally, that Cable's sentence (11-a) involves the doubling of a PP complement, which on my account is not predicted to be possible even if the PPs were to match.

These facts lead me to conclude that the Yiddish grammar cannot generate sentences with mismatched predicates. ${ }^{9}$ Consequently, such examples should not be cited as empirical evidence against a movement analysis, or in favor of an alternative analysis in which two verbs are externally merged.

\subsection{Movement and discourse function}

Many of the descriptions and analyses of Yiddish verb doubling have referred to the construction as a form of VP topicalization (Waletzky 1980; Davis and Prince 1986; Hoge 1998), and sometimes "finite verb topicalization" (Källgren and Prince 1989). A full discussion of its discourse status is beyond the scope of this article, which focuses on multiple vs. single copy pronunciation. However, it is worth mentioning that

\footnotetext{
${ }^{7}$ To illustrate that example (11-a) is only somewhat degraded, Cable cites an unrelated English sentence involving a resumptive pronoun (his example (17)) that also receives a single question mark. Braun, who also speaks English natively, told me that the Yiddish sentence is worse than the English one.

${ }^{8} \mathrm{My}$ consultants also rejected the following sentence-a version of (1-b) suggested by a reviewer as an example of a mismatch that sounds quite natural in English:
(i) *red-n a shprakh red ikh mame-loshn.
speak-INF a language speak.1.SG I mama-language
'As for speaking a language, I speak Yiddish.'

${ }^{9}$ Cable reports that mismatched predicates are also acceptable in Brazilian Portuguese. Vicente (2007:83) reports that some Spanish speakers accept sentences with mismatched genus-species predicates, as well as sentences in which the second copy of the verb appears in a coordinate structure (i.e., they accept sentences like (8-e)). Other Spanish speakers accept neither possibility, which is the case for my Yiddish consultants.
} 
predicate fronting generally requires a special pragmatic context—which explains why it can be challenging to elicit judgments on such sentences. One common function of the construction is to introduce a contrast between the predicate (which is doubled) and some previously mentioned predicate, as in the following two literary examples. The immediate context of each sentence is provided in parentheses in the translations.

(12) khotsh es-n es-n mir glaykh mit ale yidn, dos heyst: kadokhes in though eat-INF eat-1.PL we equally with all Jews that means malaria in a kleyn tepele.

a little pot

'(Among the residents of our town, we're known as the gluttons, ) but actually, we eat just like all the other Jews, i.e.: next to nothing [lit., malaria in a little pot].'

(Sholem Aleichem 1954:295)

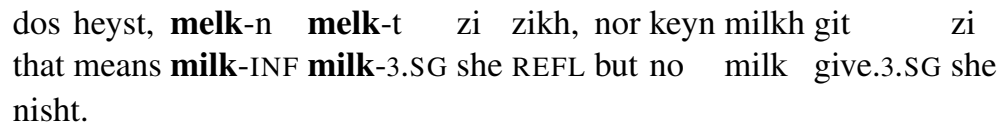

'(Our goat can't be milked anymore.) Well, actually, she can be milked, but no milk comes out.'

(Sholem Aleichem 1954:298)

These particular examples were chosen because audiobooks narrated by Yiddishspeaking actors are available online. ${ }^{10}$ The recordings make it clear that the fronted occurrence of the verb is pronounced with strong emphasis, marked by a prosodic contour known as the "rise-fall" (Burdin 2017). In these examples, there is a very steep rise in pitch with a peak on the stressed syllable of the infinitive, making the pitch range from the infinitive to the end of the clause unusually wide (Rachel Steindel Burdin, p.c.). Use of the rise-fall contour is frequently involved in topicalization, and I will assume for this analysis that the rise in both pitch and intensity is symptomatic of the verb's bearing a topic feature that also triggers movement in the syntax.

In analyses of predicate fronting, there is a tradition of translating sentences in which only the verb is pronounced in the left periphery differently than sentences in which the complement is also pronounced there: 'As for speaking, I speak Yiddish' in (1-b) vs. 'As for speaking Yiddish, I speak it' in (2). While I follow this trend here, the two structures may not necessarily have such a difference in their interpretation. For example, when asked for sentences that are natural continuations of these two examples, native speaker consultants provided identical responses (... ober ikh ken es nisht leyenen 'but I can't read it'). Even when I provided my consultants with scenarios meant to elicit the use of one but not the other structure (V vs. VP in the left periphery), consultants were reluctant to say they couldn't be used interchangeably. Again, the discourse status of the various options awaits an in-depth analysis.

\footnotetext{
${ }^{10}$ Sentence (12) is read by David Rogow, https://goo.gl/quH1 Ay, 3 minutes, 30 seconds into the recording. Sentence (13) is read by Rita Karin (same link), 9 minutes, 6 seconds.
} 
Proceeding with the assumption that the relationship between the doubled verbs in Yiddish is the result of movement, the following sections will propose explicit conditions on Spell-Out that predict which occurrence(s) of syntactic objects are pronounced in which position(s). These conditions are necessary both to illustrate why the construction is theoretically puzzling (the doubling of verbs vs. non-doubling of complements) and ultimately to highlight the predictions of independently motivated modifications to those conditions.

\section{Conditions on Spell-Out}

\subsection{Remnant movement}

The fact that complements do not double in the predicate fronting construction, shown in (14), is perhaps the least surprising facet of the predicate fronting puzzle. It is therefore a suitable starting point.
a. red-n (*mame-loshn) red ikh mame-loshn. speak-INF (*mama-language) speak.1.SG I mama-language 'As for speaking, I speak Yiddish.'
b. red-n mame-loshn red ikh (*mame-loshn).
speak-INF mama-language speak.1.SG I (*mama-language)
'As for speaking Yiddish, I speak it.'
(repeat of (2))

The unacceptability of sentences with two overt complements follows straightforwardly from a theory of syntax that allows for the fronting of incomplete (or "remnant") categories. Remnant movement is the phenomenon whereby a phrase undergoes movement only after the extraction of some smaller element from it earlier in the derivation. Consider the Yiddish sentence (15), modeled after a German sentence that has been cited as evidence for remnant movement (Müller 1998:ix, ex. 1).

$$
\begin{aligned}
& \text { [vP geleyent } \left.\mathrm{t}_{1}\right]_{2}\left[\mathrm { TP } \text { hot } [ \mathrm { DP } \text { dos } \quad \text { bukh } ] _ { 1 } \left[{ }_{\nu \mathrm{P}}\right.\right. \text { yed-er yidishist } \\
& \text { read.PTCP has the.ACC book every-NOM Yiddishist } \\
& \left.\mathrm{t}_{2}\right] \text { ]. } \\
& \text { 'EVERY YIDDISHIST read the book.' }
\end{aligned}
$$

Within the fronted VP, only the V geleyent is pronounced. The intuition is that an earlier operation extracts the DP dos bukh from the VP and generates a silent trace, which remains silent within the fronted VP. The fronted VP is thus a "remnant category" with respect to the DP. The general pattern is schematized in (16), with copies rather than traces.

$$
[\mathrm{XP} \mathrm{X}<\mathrm{YP}>] \ldots \mathrm{YP} \ldots<[\mathrm{XP} \mathrm{X}<\mathrm{YP}>]>
$$

According to the Inclusiveness Condition (Chomsky 1995:225), a principle of minimalist syntax stipulating that syntactic operations like Merge cannot generate new objects such as silent traces, all occurrences of an element like YP in (16) are syntactically identical and eligible for phonetic realization. Under typical conditions, one 
might expect Spell-Out to result in the pronunciation of the highest copy of a moved object rather than a middle one, ${ }^{11}$ although it is the middle occurrence of YP that is pronounced here.

In order to capture the intuition behind remnant movement within a minimalist framework that invokes copies rather than traces, I adopt the Spell-Out conditions of Collins and Stabler (2016). Their formalization of minimalist syntax is particularly appealing because it provides the analyst a set of precise definitions with which to evaluate the predictions of novel proposals - specifically, definitions regarding the syntactic occurrences that come to be pronounced in any given derivation. Because their formalization was not designed for Yiddish, and because the authors themselves "put aside issues such as how to handle the copies formed in predicate clefts" (Collins and Stabler 2016:71), the fact that their system can be applied to the Yiddish predicate fronting construction (albeit with one modification) lends support to it.

The Spell-Out conditions are provided in (17) and explained in the paragraphs that follow.

\section{Spell-Out conditions for phrasal movement, including remnant move- ment (based on Collins and Stabler 2016, definitions 40 and 41-c):}

a. $\mathrm{X} \in\{\mathrm{X}, \mathrm{Y}\}$ is final in a syntactic object $\mathrm{SO}$ iff there is no $\mathrm{Z}$ contained in (or equal to) $\mathrm{SO}$ such that $\mathrm{Z}$ immediately contains $\mathrm{X}$, and $\mathrm{Z}$ contains the set $\{X, Y\}$. Otherwise, $X$ is nonfinal in SO.

b. If $\mathrm{SO}=\{\mathrm{X}, \mathrm{Y}\}$ and $\mathrm{X}$ in $\mathrm{SO}$ is final in Phase but $\mathrm{Y}$ is not, Transfer $\mathrm{PF}$ (Phase, $\mathrm{SO})=\operatorname{Transfer}_{\mathrm{PF}}($ Phase, $\mathrm{X})$.

Condition (17-a) specifies the occurrences of syntactic objects (i.e., lexical item tokens or sets of such syntactic objects) that are evaluated to be "final" or "nonfinal" based on their structural positions. Condition (17-b) then states that only "final" oc-

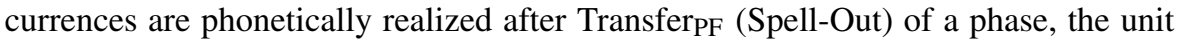
to which Transfer applies. The first condition makes reference to the notions "immediate containment" and "containment," which Collins and Stabler (2016:46) define as follows: "immediate containment" is set membership (i.e., Z immediately contains $X$ iff $X \in Z$ ), and "containment" includes both immediate containment and transitive containment extending down the tree (e.g., Z contains $\mathrm{X}$ if $\mathrm{Z}$ immediately contains $\mathrm{X}$, or if $\mathrm{Z}$ immediately contains $\mathrm{Q}$ which immediately contains $\mathrm{X}$, etc.). In other words, a syntactic object immediately contains each of its daughters, whereas a syntactic object contains each of its daughters, granddaughters, great-granddaughters, etc.

With these definitions in mind, the predictions of the Spell-Out conditions in (17) are illustrated in the following derivations. All occurrences with matching letter labels are assumed to be syntactically identical; the subscripts are for expository purposes only.

\footnotetext{
${ }^{11}$ Nunes $(1995,2004)$ discusses the rationale behind this generalization. He argues that because movement is driven by the checking of uninterpretable formal features, the highest copy will have checked the most features; general economy conditions result in the deletion of lower copies.
} 
(18)

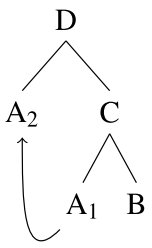

In this derivation, $\mathrm{A}_{1}$ is an element of the set $\{\mathrm{A}, \mathrm{B}\}=\mathrm{C}$ and raises to become the sister to $C$. According to $(17-a)$, the occurrence $A_{1}$ in $\{A, B\}$ is nonfinal within $D$, because there exists a syntactic object (namely $\mathrm{D}$ itself) that immediately contains $\mathrm{A}$ (the occurrence $A_{2}$ ) and also contains the set $\{A, B\}$. The occurrence $A_{2}$ in $\{A, C\}$ is final in $\mathrm{D}$, however, because there exists no syntactic object that immediately contains an occurrence of $A$ and also contains the set $\{A, C\}$. (D immediately contains an occurrence of $\mathrm{A}$, but $\mathrm{D}$ does not contain the set $\{\mathrm{A}, \mathrm{C}\}$; rather, $\mathrm{D}$ is the set $\{\mathrm{A}, \mathrm{C}\}$.) $\mathrm{B}, \mathrm{C}$, and $\mathrm{D}$ are final in D by the same reasoning. Consequently, according to (17-b), transferring $\mathrm{D}$ to $\mathrm{PF}$ will yield the phonetic realization of $\mathrm{A}_{2}$ and $\mathrm{B}$ only, as we would normally expect in simple cases of syntactic movement. ${ }^{12}$

Crucially for our purposes, the two-part definition in (17) also correctly predicts the occurrences that are pronounced under remnant movement. Consider the following derivation (19), which contains the subtree shown in (18). We will assume that $\mathrm{E}$ is a phase.

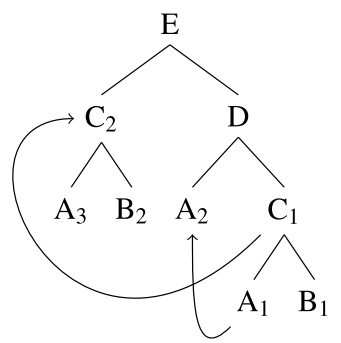

$A_{1}$ is nonfinal in $E$ because there is an object (D) that immediately contains $A_{2}$ and also contains the set $\{A, B\} . A_{2}$ is still considered final because there is no syntactic object anywhere that immediately contains an occurrence of $\mathrm{A}$ and also contains the set $\{A, C\}$. Now consider the occurrence $A_{3}$ in $\left\{A_{3}, B_{2}\right\}=C_{2}$, the moved remnant category. The occurrence $\mathrm{A}_{3}$ is nonfinal in $\mathrm{E}$ because there exists a syntactic object within $\mathrm{E}$, namely $\mathrm{D}$, that immediately contains an occurrence of $\mathrm{A}$ and also contains the set $\{A, B\}$. It follows from the same reasoning that $C_{2}, D$, and $E$ are final within $\mathrm{E}$, while $\mathrm{C}_{1}$ is nonfinal. As a result, transferring $\mathrm{E}$ to $\mathrm{PF}$ will yield overt occurrences of $\mathrm{B}_{2}$ and $\mathrm{A}_{2}$ only.

In this way, the Spell-Out conditions of Collins and Stabler (2016) correctly predict the pronunciation of occurrences under typical phrasal movement as well as remnant phrasal movement, without relying on the generation of silent traces.

\footnotetext{
${ }^{12}$ Collins and Stabler (2016) also posit a linearization algorithm (their definition 41-b) that results in specifier-head-complement order whenever sister nodes are both final. The same linearization scheme is adopted in this article.
} 


\subsubsection{Remnant movement across a phase}

One complication of this approach to pronunciation under remnant movement relates to derivation by phase. A fragment of the derivation of the Yiddish remnant movement sentence in (15) is shown in (20). Again, all occurrences of a given object are syntactically identical and numbered for expository purposes only.

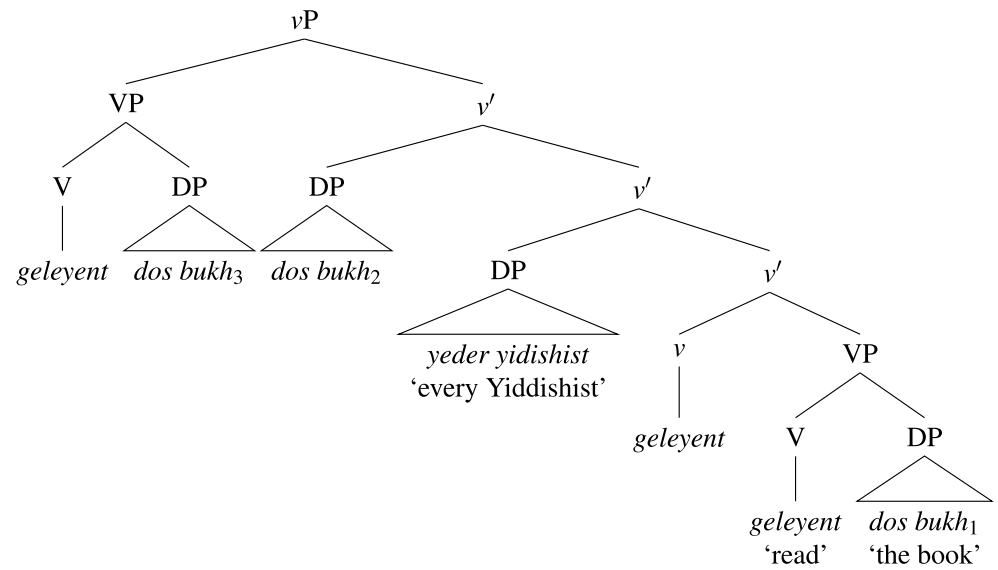

In order for the object DP dos bukh 'the book' to be pronounced above the subject DP yeder yidishist 'every Yiddishist,' and in order for the VP geleyent $<$ dos bukh> 'read <the book>' to eventually move to the left periphery, both of these phrases must move through the edge of the $v \mathrm{P}$ phase. This is because TransferpF applies to phases (17-b), and if one adopts the Phase Impenetrability Condition (PIC; Chomsky 2001:13), then any objects which remain in the domain (complement) of $v$ become inaccessible once they are spelled out. This inaccessibility could be due to the removal of syntactic structure, or to a stipulation that such structure is invisible to higher operations (Chomsky et al. 2019:240-241). In either case, this inaccessibility creates a "lethal problem" for the pronunciation of occurrences (Collins and Stabler 2016:73): if Spell-Out renders the base-generated VP in (20) inaccessible to the condition that determines the finality of occurrences (17-a), then the two higher occurrences of the DP dos bukh (marked \#2 and \#3) are both predicted to be final. DP dos bukh 2 is final in $v \mathrm{P}$ because there is no object that immediately contains an occurrence of the DP and also contains the set $\left\{\mathrm{DP}\right.$ dos bukh, [middle] $\left.v^{\prime}\right\}$. DP dos bukh $h_{3}$ in the fronted VP is also final, because the only syntactic object that immediately contains an occurrence of DP dos bukh (namely the highest $v^{\prime}$ ) does not contain the accessible set $\{\mathrm{V}$ geleyent,DP dos bukh\}. The "lethal problem" for remnant movement is therefore the doubling of the object, whenever the object and the VP move to positions out of the phase in which the VP was base-generated.

This problem-that "if an occurrence A were nonfinal before Transfer, it may become final after Transfer" (Collins and Stabler 2016:73) - leads the authors to sketch out (in an unpublished Appendix) an alternative conceptualization of Transfer that preserves syntactic structure while rendering it inaccessible to operations like Merge. However, in this article I adopt the strict assumption that any lower structure that 
has been spelled out in a phase is completely invisible for the determination of final and nonfinal occurrences at a higher phase. If this strict version of the PIC is to be maintained, then the derivation of remnant movement that causes doubling (20) must be replaced by a more optimal (less costly) alternative that does not cause doubling. A minimally different derivation is one in which the landing sites for the DP and remnant $\mathrm{VP}$ - the inner and outer $v \mathrm{P}$ specifiers, respectively—are reversed, as in (21):

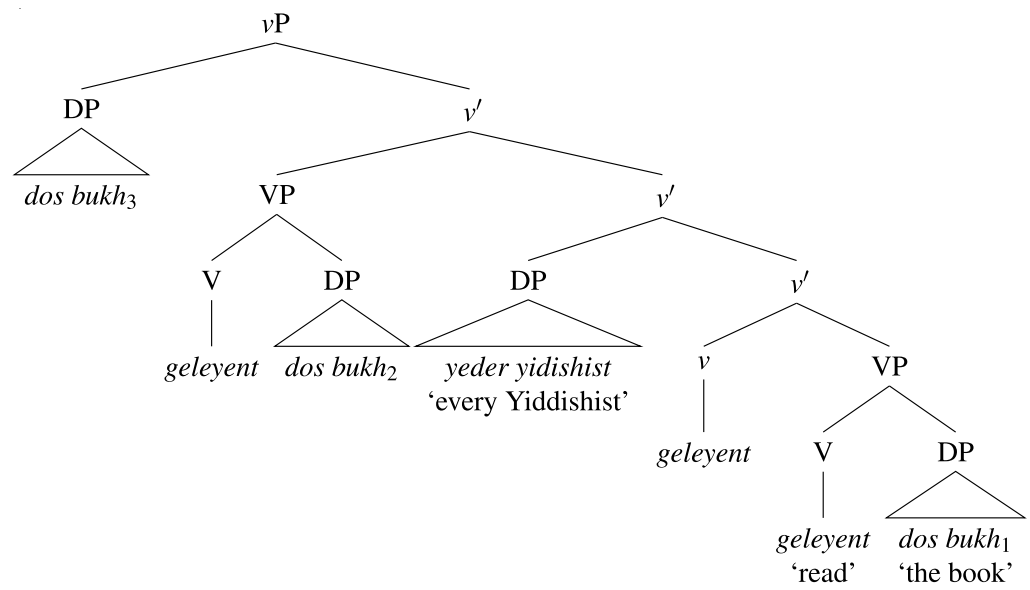

Here, the DP dos bukh 3 is final in $v \mathrm{P}$ because there is no object that immediately contains an occurrence of the DP and also contains the set \{DP dos bukh, [highest] $\left.v^{\prime}\right\}$. DP dos bukh 2 is nonfinal in $v \mathrm{P}$ because there is an object (namely $v \mathrm{P}$ itself) that immediately contains an occurrence of the DP and also contains the set $\left\{\mathrm{V}\right.$ geleyent,DP dos bukh $\left.h_{2}\right\}$. (Crucially, neither of these calculations requires the VP complement of $v \mathrm{P}$ to be accessible.) When the remnant $\mathrm{VP}$ fronts to the left periphery in Spec, TopP (not shown here), the DP dos bukh contained within that left peripheral VP will also be nonfinal, because both $\mathrm{Spec}, v \mathrm{P}$ positions will still be accessible at the TopP phase. This derivation thus yields correct predictions about remnant movement, if one adopts the Spell-Out conditions (17) and the strict assumption that spelled out structure is completely invisible for the purposes of calculating the finality of occurrences.

The structure shown in (21) could be derived in a few different ways. One would involve movement of the DP dos bukh to Spec, $v \mathrm{P}$ followed by movement of the remnant VP to an inner specifier, as in the "tucking in" approach of Richards (1999). Tucking in the VP below the landing site of the DP is difficult to define within the framework of Collins and Stabler (2016), since it requires that the $v \mathrm{P}$ object formed by movement of the DP be dismantled and subsequently reconstituted with an intervening specifier (see Collins and Stabler 2016:59, fn. 9). Another way to derive (21) is to assume that the VP moves before the DP does. For example, the VP might raise to an inner Spec, $v \mathrm{P}$ and the DP contained within it might raise to an outer Spec, $v \mathrm{P}$. This is reminiscent of smuggling, where movement of a phrase XP containing YP 
precedes the evacuation of YP from XP (Belletti and Collins 2021:3). ${ }^{13}$ However, it is not clear what could motivate the extraction of a syntactic object from an inner to an outer $v \mathrm{P}$ specifier (e.g., according to theories of Agree). ${ }^{14}$ Alternatively, the $v$ head could bear features that trigger movement of both the DP and the VP; arguably it is the VP which is attracted first, because it is closer than the DP, giving rise to the structure shown in (21) and ruling out the structure shown in (20). While I remain agnostic about which of these approaches is correct, the derivations in this article will include movement arrows suggestive of the smuggling approach. In any event, I proceed with the assumption that the $\mathrm{DP}$ and remnant $\mathrm{VP}$ escape the $v \mathrm{P}$ phase by landing at specifiers in this specific configuration, such that the DP c-commands the VP.

This discussion is not meant to redefine "remnant movement" so that it always involves three instances of movement (smuggling of XP, extraction of YP from XP, and movement of XP) rather than two (extraction of YP from XP and movement of XP). In (21), we would still say that "remnant movement" involves extraction of the DP dos bukh from the VP and subsequent fronting of the remnant VP to the left periphery (not shown). Smuggling of the VP is thus a separate step that enables correct pronunciation when remnant movement involves occurrences across multiple phases.

\subsubsection{Remnant VP movement and predicate fronting}

If the Spell-Out conditions in (17) are part of Universal Grammar, it follows that predicate fronting in Yiddish should never give rise to doubling of complements (the data are repeated in (22)).
a. red-n (*mame-loshn) red ikh mame-loshn.
speak-INF (*mama-language) speak.1.SG I mama-language
'As for speaking, I speak Yiddish.'
b. red-n mame-loshn red ikh (*mame-loshn). speak-INF mama-language speak.1.SG I （*mama-language $)$ 'As for speaking Yiddish, I speak it.'

If the complement DP mame-loshn 'mama-language' is able to undergo object shift to some intermediary position prior in the derivation to the fronting of the VP, then the occurrence of the DP contained in the fronted remnant VP will not be pronounced (yielding (22-a)). On the other hand, only if object shift does not occur is it possible, given these conditions, to pronounce an occurrence of the DP in the fronted VP (yielding (22-b)). This is essentially the analysis provided by Abels (2001) for predicate fronting in Russian and by Bondaruk (2009) for predicate fronting in Polish, in which a fronted "bare verb" is the result of remnant verb phrase movement after the evacuation of its complement.

\footnotetext{
${ }^{13}$ Smuggling analyses, including the contributions published in Belletti and Collins (2021), presuppose that there is no general freezing condition which prohibits movement out of moved constituents. See Bošković (2021) for arguments against the existence of such a general freezing ban.

${ }^{14}$ A proposed anti-locality ban on "specifier-adjunction," defined as *[XP $\left.\mathrm{YP}_{i}\left[\mathrm{XP} ¥ \mathrm{YP}_{i} \mathrm{X}^{0} \ldots\right]\right]($ Grohmann 2011:264, fn. 4), is not strictly violated by the extraction of the DP from the inner to the outer specifier.
} 
In order to account for the variation in where the complement is pronounced-it can be realized after the first or second copy of the verb-it is assumed that object shift itself is optional, consistent with the proposals of Johnson (1991:606) and Lasnik (2001). ${ }^{15}$ Independent evidence for the optionality of object shift in Yiddish comes from the following alternation:
a. er hot nisht gevolt druk-n dem artikl in forverts. he has not want.PTCP print-INF the.ACC article in Forward 'He didn't want to print the article in The Forward (newspaper).'
b. er hot nisht gevolt dem artikl druk-n in forverts. he has not want.PTCP the.ACC article print-INF in Forward 'He didn't want to print the article in The Forward.'
c. er hot dem artikl nisht gevolt druk-n in forverts. he has the.ACC article not want.PTCP print-INF in Forward 'He didn't want to print the article in The Forward.'

Sentence (23-a) suggests that the object DP dem artikl is free to remain in its basegenerated position to the right of the verb (assuming Yiddish is SVO; Diesing 1997). The acceptability of (23-b) suggests that there must be a relatively low projection that can host shifted objects. ${ }^{16}$ Finally, sentence (23-c) shows that the object can scramble past negation (presumably through $\mathrm{Spec}, v \mathrm{P}){ }^{17}$

While the conditions under which the movement of the object occurs or does not occur are beyond the scope of the current study (see Diesing 1997 for discussion), it is important to note that weak pronominal objects differ from other definite objects in that they must move to a position above negation (Diesing 1997:393-394; see Thráinsson 2001 and Vikner 2006 for parallels in other Germanic languages). This observation will become relevant shortly.
a. er ken undz nisht gut.
he know.3.SG us.ACC not good
'He doesn't know us well.'
b. *er ken nisht undz gut. he know.3.SG not us.ACC good
c. *er ken nisht gut undz. he know.3.SG not good us.ACC

\footnotetext{
${ }^{15}$ It has been posited that the short movement of objects and longer instances of object shift are motivated by independent reasons. For example, Johnson (1991) contends that short distance object shift is obligatory, driven by Case assignment, even if subsequent movements are optional. In the absence of compelling evidence from within Yiddish, I will need to assume that short distance object movement is optional. In a sentence like (23-a) where the verb also raises, its effect would not be visible.

${ }^{16}$ For proposals arguing for a low position for shifted objects, see Koster (1994), Collins and Thráinsson (1996), Lasnik (2001), Kandybowicz and Baker (2003), and Baker and Collins (2006).

${ }^{17}$ One consultant (Shvaytser) indicated that the word order in (23-b) does not seem as natural as the other two examples, which are equally unmarked. However, many sentences with precisely the structure of (23-b) were readily found in both literary texts and Hasidic Yiddish blogs. Shvaytser verified that all of the attested examples I sent him were indeed perfectly acceptable.
} 
We can see how the Spell-Out conditions in (17) would apply in the predicate fronting construction to yield the pronunciation of just one copy of the object-after the first verb or after the second, but not in both places. Consider the sentence in (25-a), where curly braces indicate that the object must be pronounced in just one of two places. A fragment of the derivation of this sentence is shown in (25-b). Optionality of object shift is indicated with a dashed arrow, a convention adopted throughout the rest of the article.

a. leyen-en $\{$ dos bukh\} leyen ikh $\{$ dos bukh $\}$. read-INF $\{$ the book $\}$ read.1.SG I the book 'As for reading $\{$ the book $\}$, I am reading $\{$ the book $\}$.'

b.

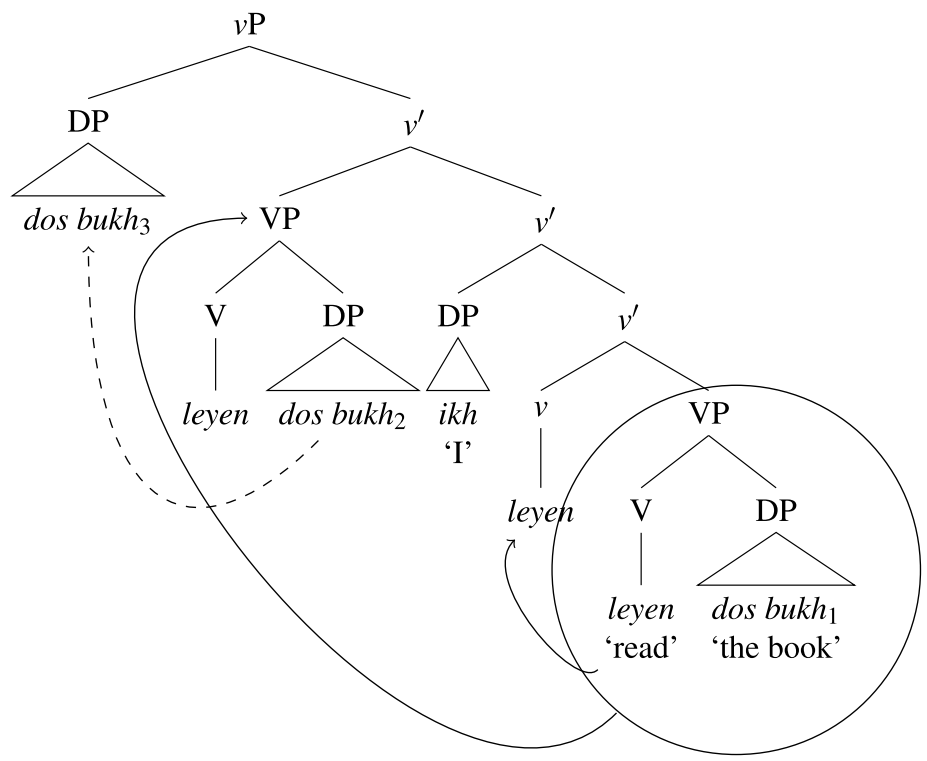

If the VP pronounced in the left periphery is the result of movement (as argued in Sect. 2), then it must move through the edge of the $v \mathrm{P}$ phase in order to be accessible for further movement. If object shift to a high projection above negation is optional, presumably the DP must also pass through the edge of the phase. (The object's ultimate landing site beyond the verb's extended projection is not shown here, and its label is not important for our purposes.)

In the derivation shown in (25-b), the VP raises to Spec, $\nu \mathrm{P}$, rendering the lower occurrence nonfinal (and silent) at Spell-Out, at which point it becomes inaccessible to higher operations. Assume that object shift (the dotted arrow) has occurred. The Spell-Out conditions in (17) predict that the occurrence DP dos bukh 3 is final in $v \mathrm{P}$. This is because there is no syntactic object anywhere that immediately contains an occurrence of the DP dos bukh and also contains the set \{DP dos bukh, [highest] $\left.v^{\prime}\right\}$. (Of course, if the object moves to some higher projection, e.g., above negation, the Spell-Out conditions predict that the object will be final and pronounced there rather 
than in Spec,vP.) The occurrence DP dos bukh 2 is nonfinal; this is because within $\nu \mathrm{P}$, there is a syntactic object ( $v \mathrm{P}$ itself) that immediately contains the occurrence $\mathrm{DP}$ dos bukh 3 and also contains the (accessible) set $\left\{\mathrm{V}\right.$ leyen,DP dos bukh $\left.h_{2}\right\}$ in its inner specifier.

However, if object shift does not occur-so that there is no occurrence DP dos $b u k h_{3}$ - then every occurrence of the DP is contained within an occurrence of VP. Without object shift, the occurrence DP dos bukh 2 is final in $v \mathrm{P}$. If the higher VP subsequently fronts to the left periphery, then the left peripheral VP will be final in TopP and it will contain the only pronounced occurrence of the DP object.

One of the predictions of this remnant movement approach to complements is that whenever object shift is obligatory, it should not be possible for the complement to be pronounced in the fronted VP. For example, because the movement of pronominal objects is obligatory (24), subsequent fronting of the VP should always be a case of remnant movement; thus the fronted VP should always contain a nonfinal (silent) occurrence of the pronominal object. This prediction is confirmed by my consultants: ${ }^{18}$
a. ken-en ken er undz.
know-INF know.3.SG he us.ACC
'As for knowing, he knows us.'
b. *ken-en undz ken er.
know-INF us.ACC know.3.SG he
c. *undz ken-en ken er.
us.ACC know-INF know.3.SG he
d. *ken-en undz ken er undz.
know-INF us. ACC know.3.SG he us. ACC
e. *undz ken-en ken er undz.
us. ACC know-INF know.3.SG he us. ACC

As this discussion has shown, the formal Spell-Out conditions of Collins and Stabler (2016) yield the predictions of remnant movement, and therefore the obligatory single copy pronunciation of DP complements in the Yiddish predicate fronting construction. In order to evaluate whether the Spell-Out conditions make correct predictions with regard to occurrences of the verb-that the verb is obligatorily pronounced in two places-we first need to ensure that the minimalist framework of Collins and Stabler (2016) can handle simple instances of head movement.

\footnotetext{
${ }^{18}$ These judgments are very strong, but intriguingly they differ from those reported by Hoge (1998), whose consultant apparently allows for the fronting of pronominal objects as long as they double. The doubling of complements is not expected to be possible under the current analysis. Previous studies of the Yiddish construction do not mention this possibility, either. Hoge (1998:92) also asserts that verb particles cannot appear in the fronted infinitive, in contrast to the data included in the conclusion section of this article and to the example sentences provided by Zaretski (1929) and Mark (1978), whom Hoge also cites.
} 


\subsection{Spell-Out conditions and head movement}

The formal conditions specifying which occurrences of syntactic objects come to be pronounced at PF (17) refer neither to phrases nor to heads. As demonstrated in the previous section, they correctly predict the pronunciation of phrasal constituents. However, it turns out that the conditions are incompatible with head movement. In fact, Collins and Stabler (2016:43) specifically mention head movement as one of the topics not addressed in their formalization due to space limitations. We will therefore need to modify Collins and Stabler's (2016) Spell-Out conditions to make correct predictions for the pronunciation of occurrences of syntactic heads before they can be applied to the verbal occurrences in the predicate fronting construction.

To demonstrate why these conditions on Spell-Out are incompatible with head movement, consider the simple case of V-to- $v$ movement shown below in (27) for the Yiddish verb phrase red mame-loshn 'speak Yiddish' (specifiers not shown).

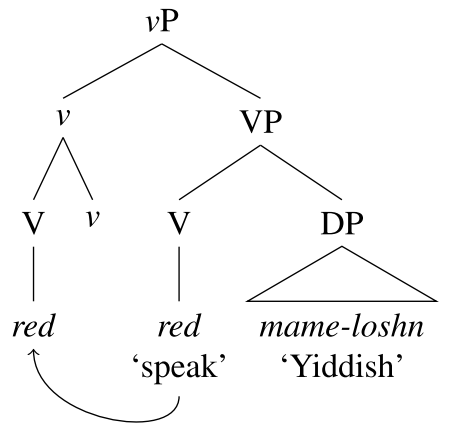

If we adopt the assumption that head movement is syntactic and involves the formation of complex head adjunction structures, ${ }^{19}$ then applying the definition of "final" (17-a) to the occurrences of $\mathrm{V}$ in (27) gives rise to an unexpected result. The left occurrence of $\mathrm{V}$ red is final, because there exists no syntactic object that immediately contains an occurrence of $\mathrm{V}$ red and also contains the set $\{\mathrm{V}$ red,v $\}$. However, the right occurrence of $\mathrm{V}$ red is also final, because there exists no syntactic object that immediately contains an occurrence of $\mathrm{V}$ red and also contains the set $\{\mathrm{V}$ red,DP mame-loshn\}. As a result, the definition given in (17-b) predicts that two copies of the head red will be pronounced. In fact, the Spell-Out conditions predict that every instance of successive-cyclic head movement will give rise to a final, and thus phonetically overt, occurrence of the moved head. This is clearly an undesirable result, since head movement does not normally give rise to the pronunciation of multiple copies.

\footnotetext{
${ }^{19}$ The syntactic adjunction analysis is a dominant approach to head movement, but not the only one. For an overview of the arguments for and against this approach, as well as alternatives involving post-syntactic (PF) movement operations, see Dékány (2018).
} 
To avoid this problem, we appeal to the observation that adjunction involves the formation of syntactic objects consisting of multiple segments: $\left.{ }_{\beta} \alpha[\beta \ldots]\right]$ (Chomsky 1986:7). Chomsky has posited an operation, Pair-Merge, to formalize such a multi-segment category whenever one object is adjoined to another:

Adjunction has an inherent asymmetry: $\mathrm{X}$ is adjoined to $\mathrm{Y}$. Exploiting that property, let us take the distinction between substitution and adjunction to be the (minimal) distinction between the set $\{\alpha, \beta\}$ and the ordered pair $<\alpha, \beta>, \alpha$ adjoined to $\beta \ldots$ For clarity, let us refer to substitution as Set-Merge and adjunction as Pair-Merge.

(Chomsky 2000:133)

The notion that Pair-Merge forms adjunction structures has been repeated in Chomsky's subsequent writings (e.g., Chomsky 2004:117-118; Chomsky 2008:146-147) and has also been assumed to apply to head movement (Chomsky 2015:12). We define Pair-Merge as follows:

\section{Pair-Merge for adjunction: \\ Pair-Merge $(X, Y)=<X, Y>$}

The most straightforward way to accommodate head movement within the Spell-Out conditions in (17) is to expand the definition of "immediate containment" to apply even in the presence of an intervening segment of a two-segment category, formed when $\mathrm{X}$ is adjoined to some other syntactic object $\mathrm{Q}$ :

\section{Immediate containment:}

$\mathrm{Z}$ immediately contains $\mathrm{X}$ iff $\mathrm{X}$ is a member of $\mathrm{Z}$ or $<\mathrm{X}, \mathrm{Q}>$ is a member of $\mathrm{Z}$.

Note that Collins and Stabler (2016:43) specifically name "Pair-Merge (adjunction)" as a topic that, like head movement, is not addressed in their formalization due to space limitations. The definitions in (28) and (29) are thus one way to fill a gap in their framework.

Returning to the head movement derivation in (27), we can already see the effect of this modification. The externally merged $\mathrm{V}$ red is nonfinal in $v \mathrm{P}$ because there exists a syntactic object (namely $v \mathrm{P}$ itself) that immediately contains $<\mathrm{V}$ red, $v>$ and also contains the set $\{\mathrm{V}$ red,DP mame-loshn $\}$. The complex $v$ head is final because there is no object that immediately contains $v$ and also contains the set $\{v, \mathrm{VP}\}$. In this way, the next higher head "counts" as an occurrence of the immediately lower head and ensures that the lower head is nonfinal.

Once again, a fragment of the derivation of the sentence (25-a) leyen-en \{dos bukh\} leyen ikh \{dos bukh\} 'As for reading \{the book\}, I am reading \{the book\}' is shown in (30) - this time with verb movement to $\mathrm{T}$ and the addition of complex head adjunction structures. Here we focus only on the occurrences of V leyen 'read' that are involved in head movement up the tree (i.e., occurrences \#1, \#2, and \#4). 
(30)

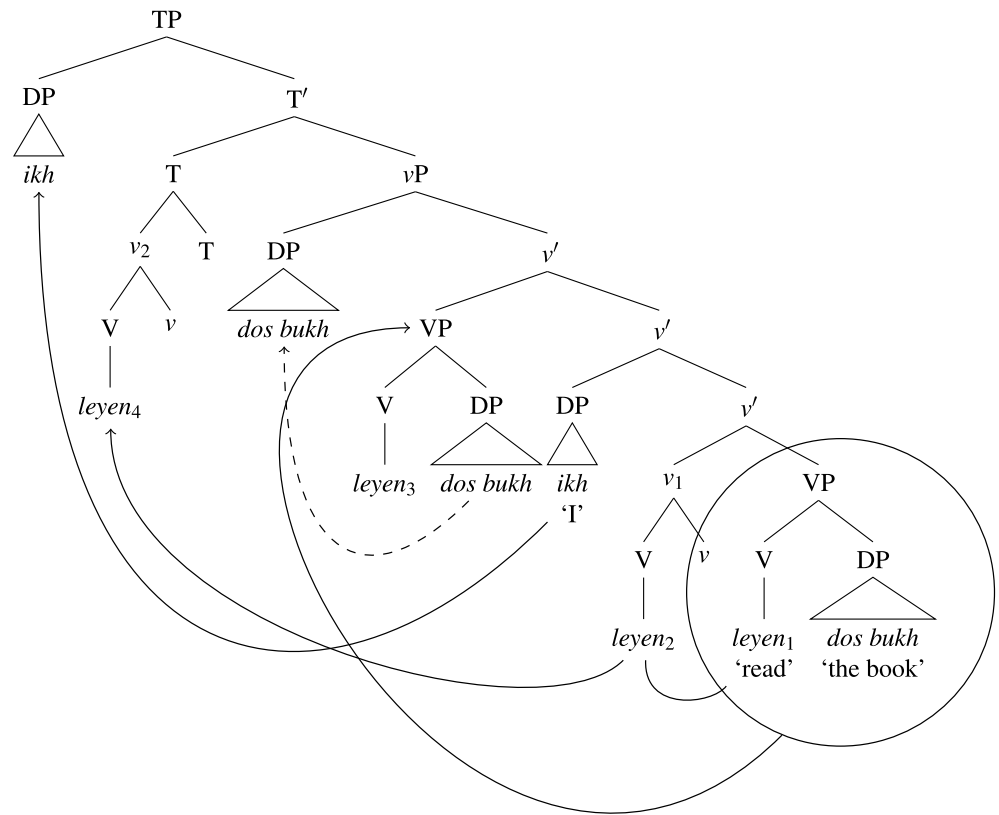

The externally merged verb in $\left\{\mathrm{V}\right.$ leyen $_{1}, \mathrm{DP}$ dos bukh $\}$ is nonfinal in the $v \mathrm{P}$ phase: there is a syntactic object (the lowest $v^{\prime}$ ) that immediately contains $<\mathrm{V}$ leyen $_{2}, v>$ and also contains the set $\left\{\mathrm{V}\right.$ leyen $_{1}, \mathrm{DP}$ dos bukh $\}$. Because $\mathrm{V}$ leyen $_{1}$ is nonfinal, when Transfer ${ }_{P F}$ applies to the phase it will be silent. The strict assumption of the PIC also means that once the lower VP is transferred to PF it is no longer visible for the purposes of calculating the finality of occurrences higher in the tree.

The next higher head, the complex $v_{1}$, is also predicted to be nonfinal in TP: this is because $\mathrm{T}^{\prime}$ immediately contains $\left\langle v_{2}, \mathrm{~T}\right\rangle$ and it also contains the set $\left\{v_{1}, \forall \mathrm{P}\right\}$ (strikethrough represents that the VP is inaccessible after phase transfer). The highest complex head, T, is final in TP: there is no syntactic object that immediately contains $\mathrm{T}$ (or any $<\mathrm{T}, \mathrm{Q}>$ ) and also contains the set $\{\mathrm{T}, v \mathrm{P}\}$.

As the verb moves successive-cyclically up the tree, forming increasingly more complex head adjunction structures, each complex head thus renders the next lower head nonfinal. $\mathrm{T}$ is the highest complex head, and it is the only one that is final. While this update to "immediate containment" makes correct predictions in simple cases of syntactic head movement, the analysis obviously does not address the classic problem of head movement's violating the Extension Condition (Chomsky 1995:190-191), since head adjunction does not extend the tree at the root. However, as a rule on SpellOut, it is both consistent with the spirit of the syntactic framework of Collins and Stabler (2016) (where finality is determined solely by structural configurations) and descriptively adequate, as it allows for a complex head to "count" as an occurrence of the next lower head and thereby render it nonfinal.

With this update in mind, we can return to the second puzzle of the Yiddish predicate fronting construction: the obligatory doubling of verbs. As will be demonstrated, the doubling of verbs actually does not require any additional modifications to the Spell-Out conditions. 


\section{Verb doubling}

Given that the conditions on Spell-Out defined thus far allow for remnant movement, the doubling of verbs seems (at first glance) to be problematic. In Sect. 2, it was claimed that predicate fronting involves the movement of a phrase rather than a bare verbal head. If the object shifts out of the VP prior in the derivation to the fronting of the VP, then the occurrence of the object in the left peripheral VP will be nonfinal. Extending this logic, if the verb moves out of the VP prior to the fronting of the $\mathrm{VP}$ - which it seems to do obligatorily, in order to move to $v$ and then to $\mathrm{T}$ where it receives tense marking - one might expect the fronted VP to be a remnant category with respect to the verb, as well. Thus the fronted VP should never contain a final (pronounced) copy of the verb; the verb should only be pronounced once, at $\mathrm{T}$.

\subsection{Against parallel chains}

One attempt to resolve this problem comes from the analysis of Aboh (2006), Kandybowicz (2008), and Aboh and Dyakonova (2009), who assume that verb doubling in the predicate fronting construction arises through parallel chain formation. According to Aboh and Dyakonova (2009), parallel chains are formed when a single syntactic occurrence (V or VP) checks the features of two different probing heads (under their analysis, Asp[ect] and Top/Foc). These two chains are believed to be formed simultaneously, and the two feature-checking relations are independent. According to their theory, the highest copy of the verb in each chain must be phonetically realized at $\mathrm{PF}$ - giving rise to doubling — while any lower occurrences are nonfinal and thus phonetically null.

In ordinary cases of VP remnant movement like (15), it is generally assumed that the object DP first raises to some specifier position (perhaps on its way to Spec,NegP), and then the remnant VP raises to an even higher specifier position (perhaps on its way to Spec,TopP). These two movement operations involve two different probes and two different goals. Under parallel chain formation, however, two different probes target the same verbal goal, $\mathrm{V}(\mathrm{P})$. It is this difference that is postulated to give rise to doubling only in the case of verbs.

Reconciling this approach with a grammar that defines the finality of occurrences based solely on syntactic structure is a major challenge. One would presumably need to define an additional condition on Spell-Out, applicable only to parallel chains, according to which two occurrences of the verb will be evaluated as final. One candidate for such a condition is given in (31).

\section{(Hypothetical) Spell-Out condition for parallel chains:}

a. Two probing features, $\mathrm{A}$ and $\mathrm{B}$, form two parallel chains by simultaneously targeting the same goal, either X or its maximal projection XP.

b. The occurrence of $X$ that is final (see (17-a)) is evaluated independently in each chain.

There are a number of reasons why such an explicit Spell-Out rule for parallel chains should be avoided. First, in order to guarantee that only the verb can have more than one final occurrence, the definition in (31) must make reference to heads of "chains," 
which are not operative in the original Spell-Out conditions. As one reviewer states, defining a new rule for parallel chains severely compromises the formal elegance of the conditions from Collins and Stabler's (2016) framework, which depend only on the structural positions of objects. The conditions in (31) essentially allow occurrences of the same syntactic object to ignore one another just in case they have been copied as the result of independent probes.

Second, the original theory of parallel chain formation by Chomsky (2008) was designed to account for parallel feature-checking operations, as in the case of whsubject movement (32), which crucially does not give rise to doubling.

$$
\begin{aligned}
& \text { a. Who saw John? } \\
& \text { b. C [T [who [v* [see John }]]]] \\
& \text { c. } \mathrm{Who}_{i}\left[\mathrm{C}\left[\mathrm{who}_{j}\left[\mathrm{~T}\left[\mathrm{who}_{k} v^{*}[\text { see John }]\right]\right]\right]\right]
\end{aligned}
$$

(Chomsky 2008:149)

Under Chomsky's analysis, $\mathrm{C}$ bears both an edge and an Agree feature that attract the goal who sitting in Spec, $v^{*} \mathrm{P}$. The Agree feature on $\mathrm{C}$ is inherited by $\mathrm{T}$, which causes an occurrence of who to raise to Spec, TP, while the edge feature of $\mathrm{C}$ causes who to raise to Spec,CP. Chomsky notes that while "there is a direct relation between who $i$ and $w h o_{k}$, and between $w h o_{j}$ and $w h o_{k}$, [there is] none between who $o_{i}$ and who ${ }_{j}$ " (Chomsky 2008:149).

Thus there is an unresolved tension between Chomsky's original formulation, which does not involve doubling, and the more recent invocations of parallel chains in the literature on predicate fronting, which do involve doubling. A parallel chains analysis in the sense of Aboh and Dyakonova (2009) (i.e., one that involves a Spell-Out condition along the lines of (31)) would predict that the occurrence of who in Spec,TP would be phonetically realized; however, as Aboh and Dyakonova (2009:1052, fn. 15) note, this contradicts the facts. In other words, it seems to be the case either that Chomsky's analysis of $w h$-subject movement does not involve parallel chains or that verb doubling does not depend on parallel chains. If they both involve parallel chains, however, then we need some principled way to explain why parallel chain formation gives rise to single copy Spell-Out in one case but multiple copy Spell-Out in the other.

The current analysis will not attempt to reconcile parallel chains with remnant movement. In fact, no additional mechanisms are needed to obtain verb doubling under predicate fronting. The modification to "immediate containment" to cover head adjunction structures (29), which was independently required in order to avoid doubling of all moved heads, is sufficient to account for both the doubling of verbs and the non-doubling of complements. This is an admittedly counterintuitive result and will therefore be illustrated using a concrete (and by now familiar) derivation of predicate fronting, showing precisely how the Spell-Out conditions apply at each step.

\subsection{Single vs. multiple copy pronunciation as predictions of the Spell-Out conditions}

The derivation for the sentence in (33-a), involving the doubling of the verb but the single copy pronunciation of the object (in one of two places), is shown in (33-b). Note that this derivation contains the subtree already presented in (30) but with the 
addition of VP fronting to a left peripheral specifier (Spec,TopP) and verb movement to Top. To prevent a cluttered tree, the only instance of movement that is explicitly shown with an arrow is optional object shift to the edge of the $v \mathrm{P}$ phase. (This could be an intermediary landing site on the object's path to a higher projection, such as the landing site between $\mathrm{T}$ and negation; not shown.)

a. leyen-en $\{$ dos bukh $\}$ leyen ikh $\{$ dos bukh $\}$. read-INF $\{$ the book read.1.SG I $\{$ the book

'As for reading $\{$ the book $\}$, I am reading \{the book\}.'

b.

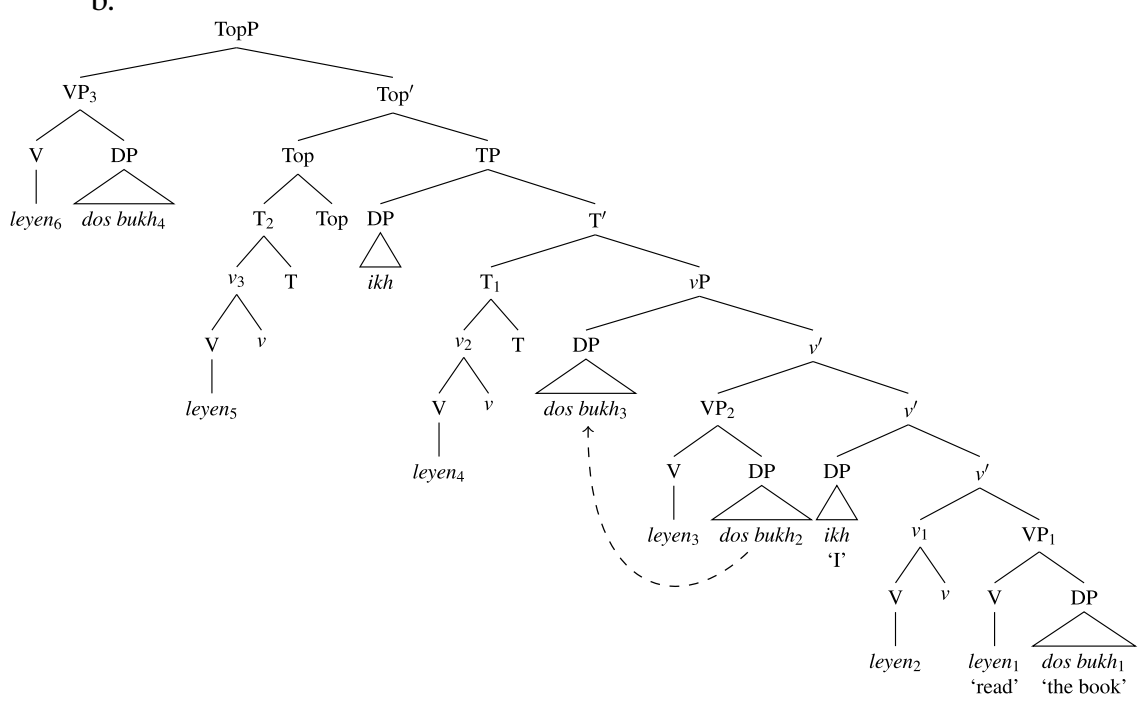

\subsubsection{Non-doubling of the complement}

Before turning to verb doubling, we will review the predictions of the Spell-Out conditions with regard to the complement, the DP dos bukh. First, let us assume that object shift (i.e., the movement indicated by the dashed arrow) does not take place; if so, every occurrence of the DP dos bukh (\#1, \#2, and \#4) is contained within an occurrence of the VP. The lowest $\mathrm{VP}_{1}$ is nonfinal in $v \mathrm{P}$, because the highest $v^{\prime}$ immediately contains $\mathrm{VP}_{2}$ and it also contains the set $\left\{v_{1}, \mathrm{VP}_{1}\right\}$. Since $\mathrm{VP}_{1}$ is in the domain of the $v$ phase and is nonfinal, it will be silent at $\mathrm{PF}$ and becomes inaccessible to further operations. Later in the derivation, $\mathrm{VP}_{2}$ raises to $\mathrm{Spec}$, TopP. $\mathrm{VP}_{2}$ is nonfinal in TopP: TopP immediately contains $\mathrm{VP}_{3}$ and it also contains the set $\left\{\mathrm{VP}_{2}\right.$, [middle] $\left.v^{\prime}\right\}$. The fronted occurrence $\mathrm{VP}_{3}$ is final because there is no syntactic object anywhere that immediately contains an occurrence of the VP and also contains the set $\left\{\mathrm{VP}, \mathrm{Top}^{\prime}\right\}$. Consequently, transferring TopP to PF will yield only one overt occurrence of the VP (\#3), including its pronounced object DP dos bukh .

Now let's assume that object shift (the dashed arrow) does take place prior to the fronting of the VP, i.e., the operations expected under remnant movement. Within the $v \mathrm{P}$ phase, the base-generated occurrence $\mathrm{DP} d o s b u k h_{1}$ is nonfinal: $v \mathrm{P}$ immediately contains DP dos bukh 3 and it also contains the set $\left\{\mathrm{V}\right.$ leyen $_{3}$,DP dos bukh $\}$. By the 
same reasoning, the occurrence DP dos bukh 2 is also nonfinal in $v \mathrm{P}$. The occurrence $\mathrm{DP}$ dos $b_{k} \mathrm{kh}_{3}$ is final: there is no syntactic object anywhere that immediately contains an occurrence of DP dos bukh and also contains the set \{DP dos bukh, [highest] $\left.v^{\prime}\right\}$. The left peripheral occurrence of the DP dos bukh 4 is nonfinal: within TopP there is an object, $v \mathrm{P}$, that immediately contains DP $d o s b u k h_{3}$ and also contains the set $\{\mathrm{V}$ leyen $_{3}$, DP dos bukh $h_{2}$. Transferring TopP to PF will thus result in the pronunciation of DP dos bukh 3 and the silence of all other occurrences. (Again, if the DP dos bukh raises to an even higher projection, it will be final there and render occurrence \#3 nonfinal.)

In either scenario-whether or not optional object shift occurs-the Spell-Out conditions correctly predict that the DP dos bukh will only be pronounced in one place, consistent with the expectation for remnant movement and the facts of (33-a).

\subsubsection{Doubling of the verb}

Having walked through the non-doubling of the complement, we now turn to the occurrences of the verb leyen 'read.' In order for the verb to double in (33-a), it must be the case that Top (dominating $\mathrm{V}$ leyen $_{5}$ ) is final, that $\mathrm{V}$ leyen $_{6}$ (inside the fronted $\mathrm{VP}_{3}$ ) is also final, and that all other occurrences of the verb are nonfinal. This is exactly what the Spell-Out conditions predict.

The externally merged $\mathrm{V}$ leyen $_{1}$ is nonfinal in the $v \mathrm{P}$ phase, because there is a syntactic object (the lowest $v^{\prime}$ ) that immediately contains an occurrence of $\left\langle\mathrm{V}\right.$ leyen $\left._{2}, v\right\rangle$ and also contains the set $\left\{\mathrm{V}\right.$ leyen ${ }_{1}, \mathrm{DP}$ dos bukh $\left.h_{1}\right\}$. As explained above, $\mathrm{VP}_{1}$ is nonfinal in $v \mathrm{P}$ due to the presence of $\mathrm{VP}_{2}$. At this point, the complement of the phase head $v_{1}$ (i.e., the nonfinal $\mathrm{VP}_{1}$ ) is transferred to $\mathrm{PF}$ and becomes invisible for the calculation of final occurrences in subsequent phases.

The complex verbal head raises to $\mathrm{T}$ and to Top, forming head adjunction structures along the way. The complex $v_{1}$ is nonfinal in the TopP phase: there is a syntactic object, $\mathrm{T}^{\prime}$, that immediately contains $<v_{2}, \mathrm{~T}>$ and also contains the set $\left\{v_{1}, \forall \mathrm{P}_{\mathrm{T}}\right\}$. The complex $\mathrm{T}_{1}$ is similarly nonfinal, due to the presence of the identical $\mathrm{T}_{2}$ adjoined to Top. Ultimately, the only complex head that is final is Top. This is because there is no projection anywhere that immediately contains Top and also contains the set $\{$ Top,TP\}. The Spell-Out conditions in (17) thus predict Top to be the only final complex head, which is exactly what would be expected under the standard assumption that only the highest head resulting from successive-cyclic movements should be pronounced.

Although the modification to the Spell-Out conditions (redefining "immediate containment") was designed to capture the facts of syntactic head movement, it also predicts a final copy of the verb in the fronted $\mathrm{VP}_{3}$ in Spec, TopP. Notice that within TopP, the only syntactic objects that immediately contain an occurrence of the verb are $\mathrm{VP}_{3}$ and $\mathrm{VP}_{2}$ (and the inaccessible $\mathrm{VP}_{1}$ ); however, these $\mathrm{VP}$ occurrences do not also contain the set $\{\mathrm{V}$ leyen,DP dos bukh $\}$ because they are that set. Top ${ }^{\prime}$ and $\mathrm{T}^{\prime}$ both contain the set $\left\{\mathrm{V}\right.$ leyen $_{3}, \mathrm{DP}$ dos bukh b $\left._{2}\right\}$, but they do not immediately contain the verb or any structure of the form $<\mathrm{V}$ leyen, $\mathrm{Q}>$. The lowest $v^{\prime}$ immediately contains such a structure, $<\mathrm{V}$ leyen $_{2}, v>$, but it does not also contain an accessible occurrence of the set $\left\{\mathrm{V}\right.$ leyen, DP dos bukh\} (as $\mathrm{VP}_{\mathrm{T}}$ is invisible to conditions applied to the TopP phase). For these reasons, V leyen 6 is final and therefore pronounced at PF. 
This protracted walk-through underscores the importance of making one's assumptions about Spell-Out totally explicit. The original conditions from Collins and Stabler (2016) yield correct predictions about the pronunciation of occurrences under remnant phrasal movement-all within a syntactic framework that assumes the copy theory of movement. However, it became clear (as the authors acknowledge) that further modifications are required to account for the pronunciation of occurrences under syntactic head movement. Once these modifications are formally defined, it is possible to apply the Spell-Out conditions to derivations of more complex constructions, like predicate fronting. This analysis has shown that the apparent contradiction of the predicate fronting construction-the doubling of verbs and non-doubling of complements - is actually a prediction of general Spell-Out conditions, applied to a derivation in which phrasal movement and head movement both take place in the syntax.

While it is clear that the Spell-Out conditions predict the doubling of the verb and non-doubling of the complement, it is worth reiterating how that is possible. What is the intuition behind the seemingly contradictory behavior of verbs and complements? Given that the verb raises in Yiddish, why does the fronted VP seem to defy the expectations of a remnant movement analysis? Recall that we have adopted a strict version of the PIC whereby transferred structure is completely invisible for the determination of final occurrences later in the derivation. For this reason, remnant movement was shown to require a derivation in which the DP c-commands the VP at the edge of the $v \mathrm{P}$ phase; a different derivation in which the VP c-commands the DP is costlier in that the Spell-Out conditions predict doubling of the DP. There are (at least) two alternative derivations that would yield DP movement to a specifier position above the VP: one involving "tucking in" the VP after the DP evacuates it, and another in which remnant movement is preceded by VP smuggling. By contrast, there is no derivation in which the verb evacuates the VP via head movement but still manages to land in a position c-commanding the raised VP. This is because the VP must raise to a $v \mathrm{P}$ specifier, which necessarily c-commands the $v$ head. In this way, the contrast between verb doubling and complement non-doubling relates to the difference between syntactic head movement and phrasal movement.

\subsection{Morphological mismatch}

One final matter that has been overlooked in the analysis thus far is the issue of morphological mismatch: although it is clear that verb doubling is predicted, the infinitival morphology realized on the fronted verb has not been addressed. One proposal comes from Abels's (2001:13) analysis of predicate fronting in Russian and Landau's (2006:47) analysis of the construction in Hebrew: infinitives are spelled out by default whenever there are no tense/agreement features on the verbal head. In Yiddish, this happens whenever there is a final occurrence of the verb at a position other than $\mathrm{T}$, including sentences where the presence of an auxiliary or modal verb blocks movement to $\mathrm{T}$. The same proposal has been made for the -en suffix spelled out in German infinitives (Biskup et al. 2011:121) and is adopted here for Yiddish. 


\subsection{Verb doubling and $d o$-support}

One of the predictions of the current approach to predicate fronting is that anytime a verb undergoes head movement and there is subsequent movement of the VP out of the phase in which it was base-generated, multiple occurrences of the verb should be pronounced. However, not all languages that allow for the fronting of VP topics exhibit doubling. One such language is German, which is closely related to Yiddish and exhibits the same movement operations discussed in this article, including remnant movement. In fact, there are attested examples of verb doubling from northeastern German dialects that parallel the examples from Yiddish (Fleischer 2008), as in (34) attributed to the novelist Fritz Reuter. However, most speakers apparently do not consider these sentences acceptable. Instead, the dominant strategy in German is to pronounce an infinitive in the left periphery and an occurrence of the verb tun 'do' with finite morphology, as in (35).

(34) Schad-en schad-t ihm das nichts.

harm-INF harm-3.SG him this not

'As for harming, it doesn't harm him.'

(Fleischer 2008:245, ex. 4)
a. Waschen tut er das Auto nie. wash.INF do.3.SG he the car never 'He never washes the car.'
(Diedrichsen 2008:221, ex. 32-a)
b. Das Auto waschen tut er nie.
the car wash.INF do.3.SG he never
'Something that he never does is wash the car.'

(Diedrichsen 2008:221, ex. 32-b)

If the sentences in (35) are to be derived using the same mechanisms outlined above for Yiddish-i.e., if both involve the fronting of a VP, either (a) as a remnant category following object shift or (b) as a full category without object shift- then what accounts for the fact that German does not generally exhibit verb doubling?

Hein (2017) directly tackles this problem of cross-linguistic variability, arguing for the existence of Chain Reduction and verbal head movement as post-syntactic operations that are applied in different orders in different languages. For German sentences like those in (35), Hein assumes that the VP is fronted. Occurrences of the VP are related by chains, and the operation Chain Reduction results in the deletion of the lower VP. In German, Chain Reduction occurs prior to head movement; because the lower VP has been deleted, there is no longer a V head that can undergo postsyntactic movement to $v$ or $\mathrm{T}$ or $\mathrm{C}$. As a Last Resort operation, German inserts a dummy verb 'do' to host inflectional information. ${ }^{20}$

\footnotetext{
${ }^{20}$ Hein (2017:20-21) states that when the complement is pronounced below the verb 'do' in a German sentence like (35-b), it is because it has moved there by phrasal movement in the narrow syntax (forming a DP chain). The fronted VP is therefore a remnant category. The reason why the complement is only pronounced once, below 'do,' is because Chain Reduction deletes the base-generated DP in the lower VP, and since the fronted VP contains a copy of this lower link of the DP chain, Chain Reduction also deletes the DP in the fronted phrase. Hein (2017:21) mentions in a footnote that "this makes Chain Reduction a very complex operation," and it warrants further explication.
} 
For a number of reasons, Hein's analysis of German is incompatible with the current analysis of Yiddish. The syntactic framework adopted (and extended) here specifically does not involve Chain Reduction (Collins and Stabler 2016:71). It also does not refer to post-syntactic movement or to repair mechanisms that force the pronunciation of syntactic objects not associated with lexical items. However, if we adopt Hein's assumption that V-to- $v$ movement is blocked in German predicate fronting, the Spell-Out conditions of (17) would correctly predict that doubling is impossible, since every occurrence of the verb would be contained within a VP, and only the fronted VP would be final.

\section{Conclusions and future directions}

This article highlighted an apparent contradiction between predicate fronting with doubling, which has been taken as strong evidence for the copy theory of movement, and remnant movement, which does not normally give rise to doubling. It was argued that the two can be reconciled using existing formalisms of minimalist syntax (Collins and Stabler 2016), which assume that syntactic movement involves copies rather than traces and that the same mechanisms underlying the pronunciation of nominal categories and phrases also underlie the pronunciation of verbal categories and heads. The general orientation to the problem of predicate fronting has been to assume that there are Spell-Out conditions that result in occurrences of syntactic objects being final (pronounced) or nonfinal (silent), based on their structural configurations within phases.

Only by defining these conditions explicitly is it possible to identify where they make incorrect predictions and require modification, as in the case of syntactic head movement, and ultimately whether novel constructions, like predicate fronting, are handled appropriately. This article has shown that the core asymmetry seen in Yiddish predicate fronting - that verbs double while complements do not-is actually expected under general Spell-Out conditions, combined with assumptions that the construction is derived via movement.

Adopting the Spell-Out conditions makes it possible to determine the occurrences of syntactic objects that are final or nonfinal. However, this does not preclude the possibility that so-called "PF repairs" may sometimes be operative, too. For example, Nunes (2004) and Bošković and Nunes (2007) have claimed that doubling can occur under morphological reanalysis, where an element undergoes movement and then fuses with an adjacent object. Consider their example of wh-copying in some varieties of German including that of the Cologne area:

$$
\begin{aligned}
& \text { Wen glaubt Hans wen Jakob gesehen hat? } \\
& \text { whom thinks Hans whom Jakob seen has } \\
& \text { 'Who does Hans think Jakob saw?' }
\end{aligned}
$$

(McDaniel 1989:569, fn. 5)

They posit that such long distance wh-movement in German arises via head adjunction of the $w h$-item to C. In contrast to the more standard approach to $w h$-movement to Spec,CP (which does not give rise to doubling), this kind of $w h$-movement is subject to negative islands. The presence of a Neg head is assumed to block this movement: 
a. Wen glaubst du nicht daß sie liebt? whom believe you not that she loves 'Who don't you think she loves?'

(Bošković and Nunes 2007:53, ex. 96-a)

b. *Wen glaubst du nicht, wen sie liebt? whom believe you not whom she loves 'Who don't you think she loves?'

(Reis 2000:395, ex. 106-a)

Whereas chain linearization would not normally result in the phonetic realization of an intermediate occurrence, Bošković and Nunes (2007) claim that the intermediate occurrence of wen in (36) undergoes morphological fusion with its sister C (as in the Distributed Morphology paradigm of Halle and Marantz 1993). Once fusion occurs, this adjoined occurrence of wen is distinct and consequently no longer involved in the computation of final occurrences in the wen chain. The two phonetically realized occurrences of wen differ only in their morphology, although this difference is not overt on the surface.

The Spell-Out conditions from Collins and Stabler (2016) rely on one rule to calculate the finality of occurrences and another rule that ensures only final occurrences are overt at PF. Of course, mechanisms that force the lexicalization of nonfinal occurrences or the silence of final occurrences - as in the Pronounce Lower Copy analysis of Bošković and Nunes (2007)_ _ could be defined as modifications to the Spell-Out conditions. In some cases, grammatical operations might render occurrences sufficiently different from one another that they are no longer considered to be copies of the same syntactic object. In other cases, there may be semantic or even prosodic mechanisms that deterministically or probabilistically render occurrences visible or invisible at PF. In fact, some of these mechanisms could help to account for Yiddish predicate fronting involving particle verbs_-novel data that await a thorough analysis. As (38) shows, predicate fronting sentences involving particle verbs can still exhibit "bare verb" doubling. (In fact, this is probably the most frequent and unmarked outcome of predicate fronting with particle verbs.) Notice that the first sentence (38-a) contains oys-trink-en out-drink-INF 'drink up', a particle verb that conveys perfective aspect, while the second sentence (38-b) contains on-heyb-n on-lift-INF 'begin,' a particle verb that is semantically non-compositional.
a. trink-en trink-t er oys a gantse flash vayn.
drink-INF drink-3.SG he out.PTCL a whole bottle wine
'As for drinking up, he is drinking up a whole bottle of wine.'
b. heyb-n heyb-t er on dem roman.
lift-INF lift-3.SG he on.PTCL the novel
'As for beginning, he is beginning the novel.'

As Yiddish grammarians Zaretski (1929:185-186) and Mark (1950, 1978) have observed, it is also acceptable to double the particle in the left periphery, as in (39). According to my consultants, the sentences in (38) and (39) are equivalent in meaning and function, although doubling the particle seems to be much less common. Note, additionally, that if the particle is doubled, the optional occurrence is in the left periphery; the lower particle must be pronounced. This suggests that the lower occurrence of the particle is always final, which would be the expectation, e.g., if 
the particle obligatorily raises out of the extended projection of the verb. If so, the fronted particle verb phrase should be a remnant category with respect to the particle, and it should always contain a nonfinal (silent) occurrence of the particle, as in (38) but contrary to (39).
a. oys-trink-en
trink-t er $*$ (oys)
a gantse flash vayn.
out.PTCL-drink-INF drink-3.SG he *(out.PTCL) a whole bottle wine
'As for drinking up, he is drinking up a whole bottle of wine.'
b. on-heyb-n heyb-t er *(on) dem roman.
on-lift-INF lift-3.SG he *(on.PTCL) the novel
'As for beginning, he is beginning the novel.'

There are many different approaches to the syntactic structure of particle verbs, including those that posit complex predicates involving incorporation of the particle and verb (sometimes with subsequent excorporation of the verb, e.g., to T) during syntactic derivations (Dehé et al. 2002). If particles and verbs incorporate variably in Yiddish, ${ }^{21}$ it may be possible to derive sentences in which the particle is doubled (39) without substantial modifications to the Spell-Out conditions cited in this article, provided that incorporation yields syntactic objects that are no longer considered to be copies of lower occurrences. In any case, whenever a mechanism forcing the lexicalization of a nonfinal occurrence is required, it should be formalized as a modification to the default Spell-Out conditions assumed to be part of Universal Grammar.

Abbreviations All example sentences from Yiddish have been transliterated according to the system of the YIVO Institute for Jewish Research (1999). Glosses follow Leipzig conventions. Non-standard abbreviations used in this article: EXPL= expletive subject; $\mathrm{PTCL}=$ particle.

Acknowledgements For their comments and suggestions, I would like to thank Stephanie Harves, Jason Kandybowicz, Itamar Kastner, Richie Kayne, Hilda Koopman, Line Mikkelsen, Eliezer Niborski, Vera $\mathrm{Zu}$, audiences at the Linguistic Society of America and NYU's Syntax Brown Bag, and anonymous peer reviewers. I owe a special debt of gratitude to Chris Collins for meeting with me to discuss my analysis at all stages of its development. I would also like to acknowledge the generosity of my language consultants, Lieb Herskovits, Binyumen Schaechter, and Yankl Shvaytser. This research has been supported in part by the National Science Foundation Graduate Research Fellowship under Grant No. DGE 1342536.

Publisher's Note Springer Nature remains neutral with regard to jurisdictional claims in published maps and institutional affiliations.

Open Access This article is licensed under a Creative Commons Attribution 4.0 International License, which permits use, sharing, adaptation, distribution and reproduction in any medium or format, as long as you give appropriate credit to the original author(s) and the source, provide a link to the Creative Commons licence, and indicate if changes were made. The images or other third party material in this article are included in the article's Creative Commons licence, unless indicated otherwise in a credit line to the material. If material is not included in the article's Creative Commons licence and your intended use is not permitted by statutory regulation or exceeds the permitted use, you will need to obtain permission directly from the copyright holder. To view a copy of this licence, visit http://creativecommons.org/licenses/by/ $4.0 \%$.

${ }^{21}$ This idea was previously suggested by Bleaman (2020:8). 


\section{References}

Abels, Klaus. 2001. The predicate cleft construction in Russian. In Annual workshop on Formal Approaches to Slavic Linguistics (FASL): The Bloomington meeting 2000, eds. Steven Franks, Tracy Holloway King, and Michael Yadroff, 1-18. Ann Arbor: Michigan Slavic Publications.

Aboh, Enoch O. 2006. When verbal predicates go fronting. ZAS Papers in Linguistics 46: 21-48.

Aboh, Enoch O., and Marina Dyakonova. 2009. Predicate doubling and parallel chains. Lingua 119(7): 1035-1065. https://doi.org/10.1016/j.lingua.2008.11.004.

Alexiadou, Artemis. 2006. Left dislocation (including CLLD). In The Blackwell companion to syntax, eds. Martin Everaert and Henk van Riemsdijk, Vol. 2, 668-699. Malden: Blackwell Sci.

Baker, Mark C., and Chris Collins. 2006. Linkers and the internal structure of $v$ P. Natural Language \& Linguistic Theory 24(2): 307-354. https://doi.org/10.1007/s11049-005-2235-1.

Bastos-Gee, Ana C. 2009. Topicalization of verbal projections in Brazilian Portuguese. In Minimalist essays on Brazilian Portuguese syntax, ed. Jairo Nunes, 161-189. Amsterdam: Benjamins. Chap. 8.

Belletti, Adriana, and Chris Collins. 2021. Introduction. In Smuggling in syntax, eds. Adriana Belletti and Chris Collins, 1-12. Oxford: Oxford University Press. https://doi.org/10.1093/oso/9780197509869. 003.0001. Chap. 1 .

Biskup, Petr, Michael Putnam, and Laura Catharine Smith. 2011. German particle and prefix verbs at the syntax-phonology interface. Leuvense Bijdragen / Leuven Contributions in Linguistics and Philology 97: 106-135. https://doi.org/10.2143/LB.97.0.2977249.

Bleaman, Isaac L. 2020. Implicit standardization in a minority language community: Real-time syntactic change among Hasidic Yiddish writers. Frontiers in Artificial Intelligence 3: 1-20. https://doi.org/10. 3389/frai.2020.00035.

Bondaruk, Anna. 2009. Constraints on predicate clefting in Polish. In Studies in formal Slavic phonology, morphology, syntax, semantics and information structure: Proceedings of FDSL 7, Leipzig 2007, eds. Gerhild Zybatov, Uwe Junghanns, Denisa Lenertová, and Petr Biskup, 65-78. Frankfurt: Peter Lang.

Bošković, Željko. 2021. On smuggling, the freezing ban, labels, and tough-constructions. In Smuggling in syntax, eds. Adriana Belletti and Chris Collins, 53-95. Oxford: Oxford University Press. https:// doi.org/10.1093/oso/9780197509869.003.0004. Chap. 4.

Bošković, Željko, and Jairo Nunes. 2007. The copy theory of movement: A view from PF. In The copy theory of movement, eds. Norbert Corver and Jairo Nunes, 13-74. Amsterdam: Benjamins.

Burdin, Rachel Steindel. 2017. New notes on the rise-fall contour. Journal of Jewish Languages 5(2): 145-173. https://doi.org/10.1163/22134638-05021184.

Cable, Seth. 2004. Predicate clefts and base-generation: Evidence from Yiddish and Brazilian Portuguese. Ms., MIT. http://people.umass.edu/scable/papers/Yiddish-Predicate-Clefts.pdf. Last accessed 8 March 2021.

Chomsky, Noam. 1986. Barriers. Cambridge: MIT Press.

Chomsky, Noam. 1995. The minimalist program. Cambridge: MIT Press.

Chomsky, Noam. 2000. Minimalist inquiries: The framework. In Step by step: Essays on minimalist syntax in honor of Howard Lasnik, eds. Roger Martin, David Michaels, and Juan Uriagereka, 89-155. Cambridge: MIT Press. Chap. 3.

Chomsky, Noam. 2001. Derivation by phase. In Ken Hale: A life in language, ed. Michael Kenstowicz, 1-52. Cambridge: MIT Press. Chap. 1.

Chomsky, Noam. 2004. Beyond explanatory adequacy. In Structures and beyond: The cartography of syntactic structures, ed. Adriana Belletti, Vol. 3, 104-131. Oxford: Oxford University Press. Chap. 3.

Chomsky, Noam. 2008. On phases. In Foundational issues in linguistic theory: Essays in honor of JeanRoger Vergnaud, eds. Robert Freidin, Carlos P. Otero, and Maria Luisa Zubizarreta, 133-166. Cambridge: MIT Press. Chap. 6.

Chomsky, Noam. 2015. Problems of projection: Extensions. In Structures, strategies and beyond: Studies in honour of Adriana Belletti, eds. Elisa Di Domenico, Cornelia Hamann, and Simona Matteini, 3-16. Amsterdam: Benjamins. https://doi.org/10.1075/la.223.01cho.

Chomsky, Noam, Ángel J. Gallego, and Dennis Ott. 2019. Generative Grammar and the Faculty of Language: Insights, questions, and challenges. Catalan Journal of Linguistics. https://doi.org/10.5565/ rev/catjl.288.

Collins, Chris, and Edward Stabler. 2016. A formalization of minimalist syntax. Syntax 19(1): 43-78. https://doi.org/10.1111/synt.12117.

Collins, Chris, and Höskuldur Thráinsson. 1996. VP-internal structure and object shift in Icelandic. Linguistic Inquiry 27(3): 391-444. 
Davis, Lori J., and Ellen F. Prince. 1986. Yiddish verb-topicalization and the notion 'lexical integrity'. In Papers from the twenty-second regional meeting, Chicago Linguistic Society, eds. Anne M. Farley, Peter T. Farley, and Karl-Erik McCullough, 90-97. Chicago: Chicago Linguistic Society.

Dehé, Nicole, Ray Jackendoff, Andrew McIntyre, and Silke Urban. 2002. Introduction. In Verb-particle explorations, eds. Nicole Dehé, Ray Jackendoff, Andrew McIntyre, and Silke Urban, 1-20. Berlin: Mouton de Gruyter.

Dékány, Éva. 2018. Approaches to head movement: A critical assessment. Glossa 3(1): 1-43. https:// doi.org/10.5334/gjgl.316.

Diedrichsen, Elke. 2008. Where is the precore slot? Mapping the layered structure of the clause and German sentence topology. In Investigations of the syntax-semantics-pragmatics interface, ed. Jr. Robert D. Van Valin, 203-224. Amsterdam: Benjamins.

Diesing, Molly. 1997. Yiddish VP order and the typology of object movement in Germanic. Natural Language \& Linguistic Theory 15(2): 369-427. https://doi.org/10.1023/A:1005778326537.

Fleischer, Jürg. 2008. Zur topikalisierenden Infinitivverdoppelung in deutschen Dialekten: Trinken trinkt er nich, aber rauchen raucht er (mit einem Exkurs zum Jiddischen). In Dialektgeographie der Zukunft: Akten des 2. Kongresses der Internationalen Gesellschaft für Dialektologie des Deutschen (IGDD) am Institut für Germanistik der Universität Wien, 20. bis 23. September 2006, eds. Peter Ernst and Franz Patocka, 243-268. Stuttgart: Franz Steiner.

Grohmann, Kleanthes K. 2011. Anti-locality: Too-close relations in grammar. In The Oxford handbook of linguistic minimalism, ed. Cedric Boeckx, 260-290. Oxford: Oxford University Press. https://doi. org/10.1093/oxfordhb/9780199549368.013.0012.

Halle, Morris, and Alec Marantz. 1993. Distributed morphology and the pieces of inflection. In The view from building 20: Essays in linguistics in honor of Sylvain Bromberger, eds. Kenneth Hale and Samuel Jay Keyser, 111-176. Cambridge: MIT Press. Chap. 3.

Hein, Johannes. 2017. Doubling and $d o$-support in verbal fronting: Towards a typology of repair operations. Glossa 2(1): 1-36. https://doi.org/10.5334/gjgl.161.

Hiraiwa, Ken, and Adams Bodomo. 2008. Object-sharing as Symmetric Sharing: Predicate clefting and serial verbs in Dàgáárè. Natural Language \& Linguistic Theory 26(4): 795-832. https://doi.org/10. 1007/s11049-008-9056-y.

Hoge, Kerstin. 1998. The Yiddish double verb construction. Oxford Working Papers in Linguistics, Philology and Phonetics 2: 85-97.

Johnson, Kyle. 1991. Object positions. Natural Language \& Linguistic Theory 9(4): 577-636. https:// doi.org/10.1007/BF00134751.

Källgren, Gunnel, and Ellen F. Prince. 1989. Swedish VP-topicalization and Yiddish verb-topicalization. Nordic Journal of Linguistics 12(1): 47-58. https://doi.org/10.1017/S033258650000192X.

Kandybowicz, Jason. 2008. The grammar of repetition: Nupe grammar at the syntax-phonology interface. Amsterdam: Benjamins.

Kandybowicz, Jason, and Mark C. Baker. 2003. On directionality and the structure of the verb phrase: Evidence from Nupe. Syntax 6(2): 115-155. https://doi.org/10.1111/1467-9612.00058.

Koster, Jan. 1994. Predicate incorporation and the word order of Dutch. In Paths towards Universal gRammar: studies in honor of Richard S. Kayne, eds. Guglielmo Cinque, Jan Koster, Jean-Yves Pollock, Luigi Rizzi, and Raffaella Zanuttini, 255-276. Washington: Georgetown University Press.

Landau, Idan. 2006. Chain resolution in Hebrew V(P)-fronting. Syntax 9(1): 32-66. https://doi.org/10. 1111/j.1467-9612.2006.00084.x.

Lasnik, Howard. 2001. Subjects, objects, and the EPP. In Objects and other subjects: Grammatical functions, functional categories and configurationality, eds. William D. Davies and Stanley Dubinsky, 103-121. Dordrecht: Kluwer Academic.

Mark, Yudel. 1950. Vegn dem infinitiv [The infinitive]. Yidishe Shprakh 10(1): 1-13.

Mark, Yudel. 1978. Gramatik fun der yidisher klal-shprakh [A grammar of Standard Yiddish]. New York: Congress for Jewish Culture. https://archive.org/details/MarkYudel.AGrammarOfStandard Yiddish1978. Last accessed 8 March 2021.

McDaniel, Dana. 1989. Partial and multiple Wh-movement. Natural Language \& Linguistic Theory 7(4): 565-604. https://doi.org/10.1007/BF00205158.

Müller, Gereon. 1998. Incomplete category fronting: A derivational approach to remnant movement in German. Dordrecht: Kluwer Academic.

Nunes, Jairo. 1995. The copy theory of movement and linearization of chains in the Minimalist Program. PhD diss., University of Maryland.

Nunes, Jairo. 2004. Linearization of chains and sideward movement. Cambridge: MIT Press. 
Ott, Dennis. 2014. An ellipsis approach to contrastive left-dislocation. Linguistic Inquiry 45(2): $269-303$. https://doi.org/10.1162/LING_a_00155.

Reis, Marga. 2000. On the parenthetical features of German was...w-constructions and how to account for them. In Wh-scope marking, eds. Uli Lutz, Gereon Müller, and Arnim von Stechow, 359-407. Amsterdam: Benjamins.

Richards, Norvin. 1999. Feature Cyclicity and the ordering of multiple specifiers. In Working minimalism, eds. Samuel David Epstein and Norbert Hornstein, 127-158. Cambridge: MIT Press. Chap. 6.

Sholem Aleichem. 1954. Ale verk fun Sholem Aleykhem [Collected works of Sholem Aleichem], Vol. 6 of Kleyne mentshelekh mit kleyne hasoges [Little people with little ideas]; Alt-nay kasrilevke [Oldnew kasrilevke]. Buenos Aires: ICUF. https://archive.org/details/nybc202588. Last accessed 8 March 2021.

Thráinsson, Höskuldur. 2001. Object shift and scrambling. In The handbook of contemporary syntactic theory, eds. Mark Baltin and Chris Collins, 148-202. Malden: Blackwell Sci. https://doi.org/10.1002/ 9780470756416.ch6. Chap. 6.

Vicente, Luis. 2007. The syntax of heads and phrases: A study of verb (phrase) fronting. PhD diss., Leiden University. https://ling.auf.net/lingbuzz/000439.

Vikner, Sten. 2006. Object shift. In The Blackwell companion to syntax, eds. Martin Everaert and Henk van Riemsdijk, Vol. 3, 392-436. Malden: Blackwell Sci. Chap. 46.

Waletzky, Joshua. 1980. Topicalization in Yiddish. In The field of Yiddish: Studies in language, folklore, and literature, eds. Marvin I. Herzog, Barbara Kirshenblatt-Gimblett, Dan Miron, and Ruth Wisse, Vol. 4, 237-315. Philadelphia: Institute for the Study of Human Issues.

YIVO (Yidisher visnshaftlekher institut). 1999. Der eynheytlekher yidisher oysleyg [The standardized Yiddish orthography], 6th edn. New York: YIVO Institute for Jewish Research and the League for Yiddish.

Zaretski, Ayzik. 1929. Yidishe gramatik: Nay-ibergearbete oysgabe [Yiddish grammar: Newly-revised edition]. Vilnius: Kletskin. https://archive.org/details/yidishegramati00zare. Last accessed 8 March 2021. 